\title{
Anatomizing Incomplete-markets Small Open Economies: Policy Trade-offs and Equilibrium Determinacy ${ }^{\star}$
}

\author{
Jaime Alonso-Carrera ${ }^{\dagger}$ and Timothy Kam*
}

\begin{abstract}
We propose a simple incomplete-markets small open economy model which is amenable to analytical dissection of its policy-relevant mechanisms. In contrast to its complete-markets limit, the equilibrium real exchange rate is irreducible from the incomplete-markets equilibrium. Market incompleteness exacerbates the domestic-inflation and output-gap monetarypolicy trade-off in two ways: its steepness and its resulting endogenous cost-push to the trade-off. The latter depends on an equilibrium combination of structural shocks and on agents' beliefs of future events. Thus, in comparison to its complete-markets and closedeconomy limits, standard Taylor-type rules are less capable of inducing determinate rational expectations equilibrium in our environment. Despite the larger policy trade-off under incomplete markets, simple policies that also respond to exchange-rate growth are able to manage expectations that drive the endogenous cost-push term. However, policies that directly respond to expectations may turn out to exacerbate the cost-push trade-off further; and thus, more likely to fuel self-fulfilling multiple or unstable equilibria.
\end{abstract}

JEL CODES: E52; F41

KEYWORDS: Incomplete Markets; Monetary Policy Isomorphism; Exchange Rate; Equilibrium Determinacy

\footnotetext{
${ }^{\dagger}$ Departamento de Fundamentos del Análisis Económico \& RGEA

Universidade de Vigo

Campus As Lagoas-Marcosende

36310 Vigo, Spain

Email: jalonso@uvigo.es ${ }^{\dagger}$

* School of Economics

H.W. Arndt Building $25 a$

The Australian National University

A.C.T. 0200, Australia

E-mail: timothy.kam@anu.edu.au*
}

\footnotetext{
${ }^{\star}$ J. Alonso-Carrera thanks the School of Economics and CAMA at the Australian National University for their hospitality during a visit where this paper was written. Financial support from the Spanish Ministry of Science and FEDER through grant ECO2011-23959; from the Spanish Ministry of Education through grant PR2009-0162; from Xunta de Galicia through grant 10PXIB30001777PR; from the Generalitat de Catalunya through grant SGR2009-1051; from EDN program funded by Australian Research Council; and from CAMA at Australian National University are gratefully acknowledged. T. Kam thanks RGEA at Universidade de Vigo for funding support and their hospitality. We thank Craig Burnside, V.V. Chari, Richard Dennis, Mark Gertler, Simon Gilchrist, Bruce Preston, Christoph Thoenissen and Tao Zha for useful suggestions and beneficial conversations. This paper evolved from an earlier version prepared for the Northwestern CIED and RBNZ Monetary Policy Conference, "Twenty Years of Inflation Targeting” held in Wellington in December 2009.
} 


\section{Introduction}

Why should small open economy monetary authorities care about international exchange rates? Is there a justification for managing exchange rates, and if possible, its expectations thereof? What is its connection to incomplete international risk sharing of country-specific shocks? In practice, in many small open economies with floating exchange rate regimes, the dynamics of the exchange rate matter, in structural modelling, and for monetary policy design. Also, it remains unclear in the literature, which monetary policy is better equipped for inducing equilibrium stability, when the dynamics of the exchange rate cannot be decoupled from inflation and output gap in an equilibrium characterization.

In standard monetary-policy small open economy models, the exchange rate is a reducible variable in equilibrium. In other words, its explicit dynamics can be decoupled from necessary equilibrium conditions. Specifically, under certain restrictions on inter- and intra-temporal elasticities of substitution, the open economy dimension merely alters the equilibrium conditions that are familiar to a closed economy model in terms of the slopes of an IS curve and a Phillips curve [see Benigno and Benigno, 2003; Galí and Monacelli, 2005; Clarida et al., 2001]. More generally, if these parametric restrictions are relaxed, Benigno and Benigno [2003] have shown that the monetary policy implication for the open economy is no longer isomorphic to its closed-economy limit. That is, the design of monetary policy for the small open economy must also take into account the trade-offs arising from the open economy channels. However, the explicit dynamics of the exchange rate is still redundant in these systems as long as the open economy has access to a complete international state-contingent asset market.

Our considerations in this paper are different to the well known question regarding the "isomorphism" between closed- and open-economy monetary policies in the context of New Keynesian models. Ours are predicated on the role of international asset market incompleteness in explaining the irreducibility of the exchange rate from an equilibrium description of a small open economy. More importantly, we ask how this single feature of market incompleteness alters well-known monetary policy trade-offs arising in complete-markets small open economy and closed economy counterparts. ${ }^{1}$ This then leads us to also ask how the feature matters for simple and operational monetary policy design, when one is concerned about equilibrium determinacy.

We propose a tractable small open economy model with incomplete international asset markets in order to address these two questions. Our model nests the canonical complete-markets

\footnotetext{
${ }^{1}$ As a corollary, we will also find that with incomplete markets, as in the more general settings with complete markets [see e.g. Benigno and Benigno, 2003; Monacelli, 2005; de Paoli, 2009b], there is a break in the monetary policy isomorphism between the small open economy and its closed economy limit.
} 
small open economy model of Clarida et al. [2001], which is similar to Galí and Monacelli [2005], and the standard New Keynesian closed economy model [see e.g. Woodford, 2003] as special cases. Our contribution is twofold.

Our first contribution is the following observation. Incomplete markets result in an irreducible and explicit exchange rate channel, in the model's equilibrium characterization. This result manifests itself in terms of two aspects relevant to monetary policy. We show that the complete-markets open economy has a less onerous domestic-inflation-to-output-gap trade-off than its closed economy counterpart. (This repeats the insights from Clarida et al. [2001] and Llosa and Tuesta [2008].) However, for all empirically plausible values of risk aversion, we also show that the incomplete-markets open economy has a steeper (conditional) trade-off relative to the same closed-economy counterpart. These new insights are obtained analytically. Second, the irreducible exchange rate channel also shows up as an endogenous cost-push term that perturbs the conditional domestic-inflation-output-gap trade-off. This cost-push term is comprised of conditional expectations of future output gap and exchange rate, along with an equilibrium combination of primitive exogenous shocks. ${ }^{2}$ As a corollary, we also obtain a break in the "monetary-policy isomorphism" between the small open economy and its closed economy limit.

As our second contribution, we show that established lessons on local stability of rational expectations equilibrium (REE) under alternative monetary policies are reversed as a result of the fact that the economy cannot completely insure country-specific risks. The latter poses additional restrictions on the admissibility of policy rules in inducing determinate REE. We show that while the inability of a small open economy to insure its country-specific technology risk reduces such admissible sets of monetary policies, it can be improved by a family of simple policies that take into account exchange rate growth as well.

The intuition for these numerical findings are given by our first observation above-that the additional constraints on policy in the incomplete-markets setting arise through: (i) an exacerbated conditional trade-off between domestic inflation and output gap; and (ii) the endogenous cost-push channel. In the incomplete-markets setting, the latter yields another means for monetary policy to prevent self-fulfilling multiple equilibria, or worse, equilibrium instability. This other means is effected through monetary policies that can "correctly" manage expectations entering the endogenous cost-push term. By smoothing out output gap and real exchange rates,

\footnotetext{
${ }^{2}$ We also consider a more general version of the model presented here. The general model admits another source through which the exchange rate may explicitly matter: The possibility of an imported input in the small economy's production structure. The model in this paper is a limit of the general model, and thus in the absence of this additional channel, an irreducible exchange rate dynamic still remains. In short, this result is purely due to the existence of incomplete international asset markets.
} 
and therefore instilling non-self-fulfilling or non-explosive conditional expectations, policies responding to growth in the exchange rate are better at inducing a determinate rational expectations equilibrium.

We thus provide a simple theoretical rationale for standard monetary policy modelling and practice in small open economies with floating exchange rates. In practice, modellers and policymakers in these economies take into account explicit exchange rate dynamics, in model equilibrium conditions, and, also in policy objectives. For example, clause 4(b) of New Zealand's 2002 Policy Targets Agreement states that: ${ }^{3}$

"[I]n pursuing its price stability objective, the Bank shall seek to avoid unnecessary instability in output, interest rates and the exchange rate".

Our analysis in this paper also complements existing studies of business cycles and/or welfare consequences of alternative monetary policies assuming incomplete-market large or small open economies [e.g. McCallum and Nelson, 1999; Chari et al., 2002; Benigno and Thoenissen, 2008; Leitemo and Söderström, 2008; de Paoli, 2009b]. While these papers focus on businesscycle accounting and/or quantifying welfare under alternative policies, there has not been a clear dissection of how a notion of market incompleteness impacts on equilibrium monetarypolicy trade-offs. Moreover, a clear exposition of the role of international asset market incompleteness in affecting REE determinacy or indeterminacy under alternative monetary-policy rules has not been studied in either the two-country or small open economy environments. ${ }^{4}$

Therefore, our contribution is to fill a gap in the literature by providing a tractable version of a small-open economy model, whose equilibrium characterization allows for a careful dissection of the role of incomplete markets in altering existing monetary policy trade-off and delivering an endogenous cost-push to that trade-off. That is, we can provide analytical and comparative policy insights with respect to well-known closed- and complete-markets openeconomy models. This then allows us to revisit and contrast with well-known results [e.g. Bullard and Mitra, 2002; Llosa and Tuesta, 2008] in terms of indeterminacy of REE under standard simple monetary policy rules.

The rest of the paper is organized as follows. In Section 2, we describe the details of our alternative model. Then we characterize competitive equilibrium in Section 3. In Section 4,

\footnotetext{
${ }^{3}$ The Reserve Bank of New Zealand pioneered inflation targeting, implementing this policy in 1990.

${ }^{4}$ An exception is Linnemann and Schabert [2004] who considered an incomplete markets small open economy with an additional predetermined state variable in the form of a net foreign asset level (i.e. current account). They showed how a simple monetary policy rule that reacts to the backward-looking state variable can help to instill a determinate REE. However, it is not precisely clear how market incompleteness in their model works with respect to monetary policy trade-offs. In contrast, we present an alternative incomplete markets model that can be analytically dissected in terms of its mechanism and its implication for monetary-policy trade-offs. Moreover, our approach allows us to also contrast with well-known complete-markets and closed-economy structures in the literature in an analytical and comparable way.
} 
we provide an analytical dissection of how asset market incompleteness in our model can result in an exacerbated and endogenous monetary policy trade-off. In Section 5, we analyze the implications of market incompleteness-and therefore the additional restrictions on stabilityinducing monetary policy rules-on equilibrium determinacy. Finally in Section 6, we conclude.

\section{Model}

Consider a small open-economy model consisting of monopolistically competitive domestic goods markets with nominal pricing rigidity, and, households that only have access to a restricted set of internationally traded non-state-contingent assets - viz. the incomplete international asset markets assumption. The domestic economy is small in the sense that local equilibrium outcomes do not have any impact on the rest of the world, but, the converse is not true. The foreign economy (or the rest of the world) is treated as a large closed economy. We will use variables with an asterisked superscript $\left(e . g . X^{*}\right)$ to refer to the foreign country and variables without an asterisk to denote the small domestic economy. Subscripts " $H$ " (for Home) and " $F$ " (for Foreign) on certain variables will denote the country of origin for quantities and their supporting prices.

\subsection{Representative household}

As in McCallum and Nelson [1999] or Benigno and Thoenissen [2008], individuals in our small open-economy have access only to a pair of domestic and foreign nominal uncontingent bonds denominated in their own currencies, respectively, $B_{t}$ and $B_{t}^{*}$. More precisely, let $h^{t}:=\left(z_{0}, \ldots, z_{t}\right)$ denote the $t$-history of aggregate shocks, where $z_{t}=\left(A_{t}, Y_{t}^{*}\right)$ is a vector of domestic productivity and foreign output levels, respectively. $B_{t+1}\left(h^{t}\right)$ or $B_{t+1}^{*}\left(h^{t}\right)$ denotes a claim on one unit of currency following $h^{t}$, and is independent of any continuation state $z_{t+1}$ that may occur at $t+1$. Let $S_{t}\left(h^{t}\right)$ denote the nominal exchange rate, defined as the domestic currency price of a unit of foreign currency. In domestic currency terms, the prices of one unit of the nominal bonds $B_{t+1}\left(h^{t}\right)$ and $B_{t+1}^{*}\left(h^{t}\right)$ are, respectively, $1 /\left[1+r_{t}\left(h^{t}\right)\right]$ and $S_{t}\left(h^{t}\right) /\left[1+r_{t}^{*}\left(h^{t}\right)\right]$, where $r_{t}$ and $r_{t}^{*}$ are the respective domestic and the foreign nominal interest rates.

The representative consumer in the domestic country faces the following sequential budget 
constraint, for each $t \in \mathbb{N}$, and each (measurable) history $h^{t}$,

$$
\begin{aligned}
P_{t}\left(h^{t}\right) & C_{t}\left(h^{t}\right)+\frac{B_{t+1}\left(h^{t}\right)}{1+r_{t}\left(h^{t}\right)}+\frac{S_{t}\left(h^{t}\right) B_{t+1}^{*}\left(h^{t}\right)}{1+r_{t}^{*}\left(h^{t}\right)} \\
& \leq W_{t}\left(h^{t}\right) N_{t}\left(h^{t}\right)+B_{t}\left(h^{t-1}\right)+S_{t}\left(h^{t}\right) B_{t}^{*}\left(h^{t-1}\right)+\Pi_{t}\left(h^{t}\right),
\end{aligned}
$$

where $P_{t}$ is the domestic consumer price indexes, $C_{t}$ is a composite consumption index, $W_{t}$ is the nominal wage rate, $N_{t}$ denotes the hours of labor supplied, and, $\Pi_{t}$ is the total nominal dividends received by the consumer from holding equal shares of the domestic firms.

A minor difference of our model to Galí and Monacelli [2005] is that consumers exhibit an endogenous discount factor that we denote by $\rho_{t}$. This assumption is introduced in order to ensure a unique nonstochastic steady-state consumption level, following Schmitt-Grohé and Uribe [2003]. ${ }^{5}$ However, this is not a fundamental assumption for our conclusions with respect to the endogenous monetary-policy trade-off arising from the real-exchange-rate channel. ${ }^{6}$ The consumers' preferences are given by the following present-value total expected utility function:

$$
\mathbb{E}_{0}\left\{\sum_{t=0}^{\infty} \rho_{t}\left\{U\left[C_{t}\left(h^{t}\right)\right]-V\left[N_{t}\left(h^{t}\right)\right]\right\}\right\}, \quad \rho_{t}=\left\{\begin{array}{ll}
\beta\left(C_{t-1}^{a}\left(h^{t-1}\right)\right) \rho_{t-1} & \text { for } t>0 \\
1 & \text { for } t=0
\end{array},\right.
$$

where $\mathbb{E}_{0}$ denotes the expectations operator conditional on time- 0 information, and, $C_{t}^{a}$ denotes the cross-economy average level of consumption.

For concreteness, we will consider the following parametric form for the function $\beta: \mathbb{R}_{+} \rightarrow$ $(0,1)$, following Ferrero et al. [2010]:

$$
\beta\left(C_{t}^{a}\right)=\frac{\bar{\beta}}{1+\phi\left(\ln C_{t}^{a}-\vartheta\right)} ; \quad \bar{\beta} \in(0,1) .
$$

\footnotetext{
${ }^{5}$ See also Lubik [2007] who expand on the results of Schmitt-Grohé and Uribe [2003] in terms of a real-businesscycle model with debt-dependent interest rate on net foreign asset positions. In contrast, Galí and Monacelli [2005] assume the existence of an international market for complete state-contingent claims. In doing so, they thus avoid the problem of steady-state allocations being dependent on initial conditions. McCallum and Nelson [1999] assume incomplete markets which would mean the opposite for steady state consumption; but this issue is not discussed by the authors. In a continuous time setting, Linnemann and Schabert [2004] also an alternative "closure" to this problem, similar to Lubik [2007], but in a sticky-price model. However, such an alternative introduces an additional predetermined state variable, and if applied to our setting, would hinder a clean dissection and comparison of the role of incomplete markets via-à-vis well-known complete-markets and closed-economy characterizations.

${ }^{6}$ Other ways of closing open-economy models are also discussed in Schmitt-Grohé and Uribe [2003]. In our framework the most natural alternative could be to assume endogenous transaction cost in taking position in foreign bonds (see, e.g., Benigno and Thoenissen [2008]). The model with this alternative assumption would be analytically less tractable, and the equilibrium dynamics requires a specific law of motion for bonds. Our assumption will make clear that what is crucial for the policy trade-off is just the incompleteness of financial markets, and not the random walk property of the asset/consumption dynamics implied by this incompleteness (in the absence of the endogenous discounting assumption).
} 
We do not impose a priori any condition on the sign of the dependence of the discount factor on average consumption, i.e., we only assume that $\beta^{\prime}\left(C_{t}^{a}\right) \neq 0$. We also assume that per-period utility of consumption and labor have the respective forms: $U\left[C_{t}\left(h^{t}\right)\right]=C_{t}\left(h^{t}\right)^{1-\sigma} /(1-\sigma)$, and, $V\left[N_{t}\left(h^{t}\right)\right]=\psi N_{t}\left(h^{t}\right)^{1+\varphi} /(1+\varphi)$, where $\sigma>0, \varphi>0$, and $\psi>0$.

The household chooses an optimal plan $\left\{C_{t}\left(h^{t}\right), N_{t}\left(h^{t}\right), B_{t+1}\left(h^{t}\right), B_{t+1}^{*}\left(h^{t}\right)\right\}_{t \in \mathbb{N}}$ to maximize (2.2) subject to (2.1). Unilaterally, the household will take the aggregate outcome $C_{t}^{a}\left(h^{t}\right)$, nominal prices $\left\{W_{t}\left(h^{t}\right), P_{t}\left(h^{t}\right), S_{t}\left(h^{t}\right)\right\}_{t \in \mathbb{N}}$ and policy $\left\{r_{t}\left(h^{t}\right)\right\}_{t \in \mathbb{N}}$ as fixed for each measurable $h^{t}$, and also the household takes $B_{0}\left(h^{0}\right)$ and $B_{0}^{*}\left(h^{0}\right)$ as given. To simplify notation hereinafter, we denote a measurable selection $X_{t}\left(h^{t}\right)=: X_{t}$ implicitly. Define the real exchange rate as $Q_{t}:=S_{t} P_{t}^{*} / P_{t}$. Given the functional forms, the respective first order conditions of the household's problem, for each $h^{t}$ and $t \in \mathbb{N}$, are:

$$
\begin{aligned}
\psi N_{t}^{\varphi} C_{t}^{\sigma} & =\frac{W_{t}}{P_{t}}, \\
C_{t}^{-\sigma} & =\left(1+r_{t}\right) \mathbb{E}_{t}\left\{\beta\left(C_{t}^{a}\right)\left(\frac{P_{t}}{P_{t+1}}\right) C_{t+1}^{-\sigma}\right\}, \\
C_{t}^{-\sigma} & =\left(1+r_{t}^{*}\right) \mathbb{E}_{t}\left\{\beta\left(C_{t}^{a}\right)\left(\frac{P_{t}^{*} Q_{t+1}}{P_{t+1}^{*} Q_{t}}\right) C_{t+1}^{-\sigma}\right\} .
\end{aligned}
$$

Each optimally chosen $C_{t}$ will be consistent with the household's intra-period choice of a home-produced final consumption good, $C_{H, t}$ and an imported final good $C_{F, t}$, where $C_{t}$ is defined by a CES aggregator

$$
C_{t}=\left[(1-\gamma)^{\frac{1}{\eta}}\left(C_{H, t}\right)^{\frac{\eta-1}{\eta}}+\gamma^{\frac{1}{\eta}}\left(C_{F, t}\right)^{\frac{\eta-1}{\eta}}\right]^{\frac{\eta}{\eta-1}} ; \quad \gamma \in(0,1), \eta>1 .
$$

Furthermore, each type of final good, $C_{H, t}$ and $C_{F, t}$, are aggregates of a variety of differentiated goods indexed by $i, j \in[0,1]$. Respectively, these aggregates are $C_{H, t}=\left[\int_{0}^{1} C_{H, t}(i)^{\frac{\varepsilon-1}{\varepsilon}} d i\right]^{\frac{\varepsilon}{\varepsilon-1}}$, and $C_{F, t}=\left[\int_{0}^{1} C_{F, t}(j)^{\frac{\varepsilon-1}{\varepsilon}} d j\right]^{\frac{\varepsilon}{\varepsilon-1}}$, where $\varepsilon>1$. As is well known from Galí and Monacelli [2005], optimal allocation of the household expenditure across each good type gives rise to static demand functions for $\left(C_{H}(i), C_{F}(i), C_{H}, C_{F}\right)$ and price indexes. Details of these demand functions and prices are given in our online Supplementary Appendix (see section A).

\subsection{Differentiated goods technology and pricing}

We assume a production sector similar to Galí and Monacelli [2005]. This is purely to keep our expositions later transparent and comparable to the mainstream models in the literature 
[i.e. Galí and Monacelli, 2005; Clarida et al., 2001; Llosa and Tuesta, 2008]. ${ }^{7}$ Each domestic firm $i \in[0,1]$ produces a differentiated good. Production is represented by a linear technology

$$
Y_{t}\left(i, h^{t}\right)=A_{t} N_{t}^{d}\left(i, h^{t}\right)
$$

where $N_{t}^{d}\left(i, h^{t}\right)$ is labor hired by the firm; and the random variable $A_{t}:=\exp \left\{a_{t}\right\}$ is an exogenous embodied labor productivity. With a homogeneous of degree one production function the first-order conditions (for cost minimization with respect to labor) can be written in the aggregate as

$$
\frac{W_{t}\left(h^{t}\right)}{P_{t}\left(h^{t}\right)}=\frac{M C_{t}^{n}\left(h^{t}\right)}{P_{t}\left(h^{t}\right)} A_{t}
$$

where $M C_{t}^{n}$ is nominal marginal cost.

Since each firm $i \in[0,1]$ is assumed to be imperfectly competitive, it gets to set an optimal price $P_{H, t}\left(i, h^{t}\right)$ given a Calvo-style random time-independent signal to do so. With a perperiod probability $(1-\theta)$ the firm gets to reset price. For every date $t$ and history $h^{t}$, the firm's optimal pricing decision is characterized by a first-order condition:

$$
\mathbb{E}_{t}\left\{\sum_{k=0}^{\infty} \theta^{k}\left(\prod_{\tau=t}^{t+k-1} \beta\left(C_{\tau}^{a}\right)\right) \frac{\xi_{t+k}}{\xi_{t}} Y_{t+k}(i)\left[\tilde{P}_{H, t}(i)-\left(\frac{\varepsilon}{\varepsilon-1}\right) M C_{t+k}^{n}\right]\right\}=0,
$$

where $\xi_{t}:=U_{C}\left(C_{t}\right)$, and the demand faced by the firm at some time $t+k$ (and following history $\left.h^{t+k}\right)$, conditional on the firm maintaining a sale price of $\tilde{P}_{H, t}(i)$ is

$$
Y_{t+k}(i)=\left(\frac{\tilde{P}_{H, t}(i)}{P_{H, t+k}}\right)^{-\varepsilon}\left[C_{H, t+k}+C_{H, t+k}^{*}\right]
$$

In a symmetric pricing equilibrium, where $\tilde{P}_{H, t}:=\tilde{P}_{H, t}\left(h^{t}\right)=\tilde{P}_{H, t}\left(i, h^{t}\right)$, the law of motion for the aggregate price is $P_{H, t}=\left[\theta P_{H, t-1}^{1-\varepsilon}+(1-\theta) \tilde{P}_{H, t}^{1-\varepsilon}\right]^{\frac{1}{1-\varepsilon}}$. As this part of the model is quite standard in the literature, we derive the details separately (see Supplementary Appendix B).

\subsection{Market clearing}

In a competitive equilibrium we require that given monetary policy and exogenous processes, the decisions of households and firms are optimal, as characterized earlier, and that markets clear. First, the labor market must clear, so that (2.4) equals (2.9) for all states and dates:

\footnotetext{
${ }^{7}$ In the online Supplementary Appendix to this paper we consider a more general production model, which admits domestic labor and imported intermediate factors of productions as in McCallum and Nelson [1999]. Qualitatively, this will not matter for the implications of incomplete asset markets for our monetary policy trade-off. In fact, the extension generalizes our main points and conclusions in this paper.
} 
$N_{t}\left(i, h^{t}\right)=N_{t}^{d}\left(i, h^{t}\right)$. Second, the final Home-produced goods market for each variety $i \in[0,1]$ clears so that:

$$
Y_{t}\left(i, h^{t}\right)=C_{H, t}\left(i, h^{t}\right)+C_{H, t}^{*}\left(i, h^{t}\right)
$$

Third, the no-arbitrage condition for international bonds will be given by the equality of (2.5) and (2.6). In the rest of the world, assumed to be the limiting case of a closed economy, we have market clearing as $Y_{t}^{*}=C_{t}^{*}$.

\section{Local equilibrium dynamics}

In this section we characterize the log-linearized rational expectation equilibrium (REE) dynamics of our small open-economy. To this end, consider the gap between each aggregate variable and its respective potential level defined in an equilibrium with fully flexible domestic prices - i.e. when the percentage deviation (from steady state) of real marginal cost, denoted by $m c_{t}$, is zero at any time $t$ and in any state. Let lowercase variables denote the percentage deviation of its level $X$ from its nonstochastic steady state point $X_{s s}$, e.g. $x:=\ln \left(X / X_{s s}\right)$. Define the potential output and the real exchange rate, respectively, $\bar{y}_{t}$ and $\bar{q}_{t}$, as the levels of output and real exchange rate, respectively, at the flexible-price equilibrium. It can be shown that the levels of both $\bar{y}_{t}$ and $\bar{q}_{t}$ only depend on exogenous variables. Let $\widetilde{x}_{t}$ and $\widetilde{q}_{t}$ denote the domestic output gap and the real exchange rate gap (in percentage deviation), respectively, where $\widetilde{x}_{t}=y_{t}-\bar{y}_{t}$ and $\widetilde{q}_{t}=q_{t}-\bar{q}_{t}$. The REE characterization can be approximated to first-order accuracy as a system of forward-looking stochastic dynamic equations for $\widetilde{x}_{t}, \pi_{H, t}$ and $\widetilde{q}_{t}$. (Derivations are provided in Supplementary Appendix C.)

Definition 1 (Incomplete Markets (IM)) Given a monetary policy process $\left\{r_{t}\right\}_{t \in \mathbb{N}}$ and exogenous processes $\left\{\epsilon_{t}, u_{t}\right\}_{t \in \mathbb{N}}$, a (locally approximate) rational expectations competitive equilibrium (REE) in the IM model is a bounded stochastic process $\left\{\pi_{H, t}, \widetilde{x}_{t}, \widetilde{q}_{t}\right\}_{t \in \mathbb{N}}$ satisfying:

$$
\begin{aligned}
\pi_{H, t} & =\bar{\beta} \mathbb{E}_{t}\left\{\pi_{H, t+1}\right\}+\lambda\left(\kappa_{1} \widetilde{x}_{t}+\kappa_{2} \widetilde{q}_{t}\right), \\
\widetilde{x}_{t} & =\omega \mathbb{E}_{t}\left\{\widetilde{x}_{t+1}\right\}-\mu\left[r_{t}-\mathbb{E}_{t}\left\{\pi_{H, t+1}\right\}\right]+\chi \mathbb{E}_{t}\left\{\widetilde{q}_{t+1}\right\}+\epsilon_{t}, \\
\widetilde{q}_{t} & =\mathbb{E}_{t}\left\{\widetilde{q}_{t+1}\right\}-(1-\gamma)\left[r_{t}-\mathbb{E}_{t}\left\{\pi_{H, t+1}\right\}\right]+u_{t} .
\end{aligned}
$$

where $\bar{\beta}=\beta\left(C_{s s}\right)$,

$$
\lambda=\frac{(1-\theta)(1-\theta \bar{\beta})}{\theta}
$$




$$
\begin{gathered}
\kappa_{1}=\varphi+\frac{\sigma}{1-\gamma}, \quad \kappa_{2}=-\frac{\sigma \eta \gamma(2-\gamma)}{(1-\gamma)^{2}}+\frac{\gamma}{(1-\gamma)} ; \\
\omega=\frac{\sigma}{\sigma-\phi^{\prime}}, \quad \mu=\left[\frac{1-\gamma}{\sigma-\phi}\right]\left[1-\gamma+\frac{\eta \gamma(2-\gamma)(\sigma-\phi)}{1-\gamma}\right], \quad \text { and }, \quad \chi=\frac{\eta \gamma \phi(2-\gamma)}{(1-\gamma)(\sigma-\phi)} .
\end{gathered}
$$

Consider the equilibrium IS functional equation (3.2). In our small open economy the real exchange rate indirectly affects the output gap via the ex-ante real interest rate (through $\mu$ ). This indirect channel is similar to the standard models of Galí and Monacelli [2005] and Clarida et al. [2001], and, depends on the degree of openness $\gamma$. Note however, movements in the conditional expectation of the real exchange rate in our model also affect the output gap (via $\chi$ ) directly: (i) by modifying the marginal rate of substitution of consumption between different periods and across states (i.e. $\phi$ ); and (ii) the interaction of these effects with the substitution between home and foreign-produced good (via $\eta$ ). This direct channel is just an artefact of the endogenous discount rate model, and, is negligible when we assume the limiting case for the elasticity of the discount rate with respect to aggregate consumption, $\phi \searrow 0$. In this case, $\chi \approx 0$. This assumption follows Ferrero et al. [2010]. Furthermore, $\phi$, affects the elasticities of output gap with respect to the ex-ante real interest rate $\mu$. Again, with $\phi \searrow 0$, this indirect channel introduced by endogenous discounting will be negligible.

Equation (3.1) is an augmented New Keynesian Phillips curve representing the dynamics of the short-run aggregate supply. Consider first, the term $\lambda \kappa_{1}$ representing the direct equilibrium link between output gap and domestic inflation. This term has the textbook interpretation of a conditional slope of the Phillips curve in output-gap-domestic-inflation space. It indexes the domestic-inflation-output-gap (or monetary policy) trade-off. This trade-off connects the domestic labor market equilibrium relation (hence the dependency of $\kappa_{1}$ on $\varphi$ and $\sigma$ ) and goods market clearing (hence $\gamma$ ) to firm's wage bill (or real marginal cost) and their optimal pricing plans. For example, when output demand gap $\tilde{x}_{t}$ goes up, all else unchanged, there is a rise in the domestic firms' demand for labor input to meet the rise in demand for their final goods. This raises the firms' real marginal cost and therefore domestic inflation, as some firms can and optimally would like to readjust prices upward to maintain their optimal markup plan. Variation in $\tilde{x}_{t}$ also has effects on the real exchange rate. Hence the degree of openness $\gamma$ further steepens this domestic-inflation-output-gap trade-off. This feature is also common to standard complete markets models [e.g. Clarida et al., 1999, 2001].

Next, consider the term involving $\kappa_{2}$ which is only present in the IM economy. This direct link between real exchange rate movements and the real marginal cost encapsulates two effects arising from demand channels corresponding to the two terms in the composite parameter $\kappa_{2}$ in equation (3.1). Consider an increase in the (current) real exchange rate-i.e. an exchange 
rate depreciation. This increases the relative prices of the imported consumption goods faced by domestic consumers. This effect has a substitution and a wealth effect on real marginal cost, and thus on domestic inflation in the equilibrium Philips curve (3.1). On the one hand (i.e. the first term in $\kappa_{2}$ ), this leads consumers to reduce the demand for imported goods, and therefore to reduce aggregate consumption and to substitute it for more leisure. This translates into an increase in marginal product of labor that drives the marginal cost up. On the other hand (i.e. the second term in $\kappa_{2}$ ), this relative increase in the price of imported consumption goods reduces the real wage income faced by consumers, who would react by increasing labor supply in response to a lower purchasing power of their given income. This leads to a reduction in the marginal product of labor, which pushes the marginal cost down.

Observe that the substitution effect dominates if agents are sufficiently risk averse-i.e. $\sigma>$ $(1-\gamma) /[\eta(2-\gamma)])$ so that $\kappa_{2}<0$. This implies that the effect of an increase in the relative price of the imported consumption goods on marginal cost is always negative. Therefore, the overall impact of the real exchange rate on domestic inflation will also be negative. ${ }^{8}$ Moreover, the larger is the measure of agents' risk aversion $\sigma$, the more sensitive is the previously discussed domestic-inflation-output-gap (or monetary-policy) trade-off, which is indexed by $\kappa_{1}$, to the real exchange rate. That is, we can imagine the monetary-policy trade-off shifting around more, the more sensitive it is to real exchange rate movements-i.e. larger $\kappa_{2}$. In Section 4 , we will relate to these observations again when we study the role of market-incompleteness in affecting the policy trade-off.

Therefore, in contrast to standard models in the literature, we do not need to assume exogenous "cost-push shocks" in order to create a non-trivial monetary policy trade-off. ${ }^{9}$ Moreover, in contrast to standard open-economy models, [e.g. Benigno and Benigno, 2003; Galí and Monacelli, 2005; de Paoli, 2009a], the relevant monetary-policy trade-off embedded in the Phillips curve- between $\widetilde{x}_{t}$ and $\pi_{H, t}$-is now perturbed by an endogenous "cost-push" channel (via $\left.\lambda \kappa_{2}\right) \cdot{ }^{10}$

\footnotetext{
${ }^{8}$ When we generalize the production side to include imported intermendiate inputs, the sign of $\kappa_{2}$ is then ambiguous, and it depends on the degree of openness $\gamma$ and the share of imported intermediate inputs $(1-\alpha)$. For empirically plausible parametrization, we show that in such a more general model, the overall sign of this slope is still negative.

${ }^{9}$ See Clarida et al. [1999, 2001] for a detailed discussion on this ad-hoc cost-push term.

${ }^{10}$ In our model the real marginal cost is not fully tied to the output gap but also depends on the real exchange rate as is shown in Section C of the supplementary appendix. Moreover, as (3.3) shows, the dynamics of the real exchange rate depends on the exogenous variable $u_{t}$ given some endogenous nominal interest rate $r_{t}$ policy outcome. This feature of our model does not rely on price stickiness in an additional imported goods sector as in Monacelli [2005].
} 


\section{Dissecting the IM mechanism}

We will now study the role of international asset-market incompleteness in this model in two parts. In Section 4.1, we demonstrate how IM implies an irreducible (i.e. explicit) real exchange rate channel. This is done by contrast to its two limit-economy observations-a completemarkets (CM) model and a closed (CD) economy model. In Section 4.2, we complete the study by looking at what these limit economies mean for comparative monetary policy trade-offs across the three models. The following exposition on IM's exchange-rate irreducibility and IM's limit CM and CD economies will allow us to form sharper insights into how market incompleteness alters monetary-policy trade-offs relative to the well-known CM and CD assumptions. These insights will be useful for understanding the results of our experiments on alternative monetary policies and equilibrium determinacy later.

\subsection{Two limit economies of IM}

The IM model nests familiar complete-markets [e.g. Clarida et al., 2001] and closed-economy [e.g. Woodford, 2003] counterparts. Let $\kappa_{1}$ and $\kappa_{2}$ be as stated in Definition 1.

In the complete markets (CM) version of our model, complete international risk sharing results in a tight link between the real exchange rate and the marginal rate of substitution between cross-country consumption, $q_{t}=\sigma\left(c_{t}-c_{t}^{*}\right)$, in every date and state of the nature. ${ }^{11}$

Using this relationship and from market clearing, we obtain that

$$
y_{t}=\frac{(1-\gamma)^{2}+\sigma \eta \gamma(2-\gamma)}{\sigma(1-\gamma)} q_{t}+y_{t}^{*}
$$

Equation (4.1) also holds when output and the real exchange rate are at their respective potentials, $\bar{y}_{t}$ and $\bar{q}_{t}$. Since $y_{t}^{*}$ is exogenous and assuming it is at its potential level, this implies that output gap is proportional to the real exchange rate gap, or

$$
\tilde{q}_{t}=\frac{\sigma(1-\gamma)}{(1-\gamma)^{2}+\sigma \eta \gamma(2-\gamma)} \tilde{x}_{t} \equiv \tau \tilde{x}_{t}
$$

Using this fact we arrive at the following characterization of a REE for the CM economy:

Proposition 1 (Complete Markets (CM)) If the small open economy has access to complete international Arrow securities, then the real exchange rate is reducible from-i.e. it has no direct role in-the

\footnotetext{
${ }^{11}$ With complete markets, the Euler condition (within the conditional expectations operator) in (2.5) will in fact hold for every state of nature, following every history, such that equating the Home Euler condition to that of the rest of the world, one can derive the condition that $Q_{t}=\left(C_{t}^{*} / C_{t}\right)^{-\sigma}$, and a log-linear transform of this expression is $q_{t}=\sigma\left(c_{t}-c_{t}^{*}\right)$.
} 
dynamic characterization of equilibrium. The competitive equilibrium is then described by

$$
\begin{aligned}
\pi_{H, t} & =\bar{\beta} \mathbb{E}_{t}\left\{\pi_{H, t+1}\right\}+\lambda \kappa^{C M} \widetilde{x}_{t} \\
\widetilde{x}_{t} & =\omega \mathbb{E}_{t}\left\{\widetilde{x}_{t+1}\right\}-\mu^{C M}\left[r_{t}-\mathbb{E}_{t}\left\{\pi_{H, t+1}\right\}\right]+\epsilon_{t},
\end{aligned}
$$

where

$$
\begin{aligned}
\kappa^{C M} & =\frac{\sigma}{(1-\gamma)^{2}+\sigma \eta \gamma(2-\gamma)}+\varphi \equiv \kappa_{1}+\tau \kappa_{2}, \quad \tau:=\frac{\sigma(1-\gamma)}{(1-\gamma)^{2}+\sigma \eta \gamma(2-\gamma)}, \\
\mu^{C M} & =\left[\frac{1-\gamma}{\sigma-\phi(1-\gamma)}\right]\left[1-\gamma+\frac{\eta \gamma \sigma(2-\gamma)}{1-\gamma}\right] .
\end{aligned}
$$

The first term on the right of $\kappa^{C M} \equiv \kappa_{1}+\tau \kappa_{2}$ in (4.5) captures the direct link between output gap on domestic inflation. This channel is common with its counterpart in the IM model which was explained earlier. In contrast to IM, the second term in $\kappa^{C M}$ captures a compound effect. Recall that in the IM economy, since real exchange rate variation $\tilde{q}_{t}$ is explicitly decoupled from output gap $\tilde{x}_{t}$ (due to incomplete international risk sharing), then exogenous shocks causing movements in $\tilde{q}_{t}$ would directly impact on domestic inflation via the equilibrium trade-off term $\kappa_{2}$. However, as we showed in (4.2), under $\mathbf{C M}$, complete international risk sharing means that movements in $\tilde{q}_{t}$ is directly absorbed in $\tilde{x}_{t}$, reflecting equilibrium shifts of state-contingent allocations that satisfy the state-by-state and date-by-date no-arbitrage asset pricing restriction. Therefore any impact of movements in $\tilde{q}_{t}$ on domestic inflation-i.e. $\kappa_{2}$ in the equivalence in (4.5)—will only arise indirectly via domestic output gap adjustments in the CM economy-i.e. the compound term $\tau \kappa_{2}$.

Observe that these indirect effects of the real exchange rate in the dynamic of the domestic inflation (3.1) through marginal cost disappear when $\gamma=0$. Furthermore, if $\phi=0$, then there is no direct real exchange rate channel in the IS relation (3.2) as well. Moreover, Clarida et al. [2001] have shown that such an economy is qualitatively similar to the CM economy. That is:

Proposition 2 (Closed Economy (CD)) If the economy (i) does not rely on imported final consumption goods, $\gamma=0$, and (ii) thus endogenous discounting is an irrelevant assumption (i.e. $\phi=0$ ), then the model is equivalent to the canonical new-Keynesian closed-economy model.

$$
\begin{aligned}
\pi_{H, t} & =\bar{\beta} \mathbb{E}_{t}\left\{\pi_{H, t+1}\right\}+\lambda \kappa^{C D} \widetilde{x}_{t} \\
\widetilde{x}_{t} & =\omega \mathbb{E}_{t}\left\{\widetilde{x}_{t+1}\right\}-\mu^{C D}\left[r_{t}-\mathbb{E}_{t}\left\{\pi_{H, t+1}\right\}\right]+\epsilon_{t},
\end{aligned}
$$


where

$$
\kappa^{C D}=\varphi+\sigma, \quad \mu^{C D}=\frac{1}{\sigma^{\prime}}, \quad \omega=1
$$

This limit economy is isomorphic to the complete-markets small open economy characterized by (4.3) and (4.4).

Finally, note that our model admits another source through which the exchange rate may explicitly matter: the endogenous discount factor channel. However, as discussed earlier, this remains inconsequential to this result (i.e. when $\phi \searrow 0$ ). That is, if the endogenous discounting were not present, an irreducible exchange rate dynamic still remains; and the latter is purely a result from the existence of incomplete international asset markets.

\subsection{Limit economies and comparative policy trade-offs}

We are now ready to discuss comparative monetary-policy trade-offs between IM and its limit economies: CM and CD. These comparisons can be conveniently cast in terms of the constantrelative-risk-aversion (CRRA) parameter $\sigma$. That is, under specific values of $\sigma$ we would have, respectively, an equivalence between IM and $\mathbf{C M}$ and an equivalence between $\mathbf{I M}$ and $\mathbf{C D}$ in terms of REE and monetary-policy trade-offs. For values of $\sigma$ away from these demarcating equivalence points, we can compare monetary-policy trade-offs implied by these three economies' different REE. ${ }^{12}$ We will also discuss which of all the cases of REE policy tradeoffs considered are relevant for quantitatively plausible values of $\sigma$.

In the following observations, we maintain the assumption of $\phi \searrow 0$, which was justified earlier. First, consider the case when IM has the same REE characterization as CM. From Definition 1 and Proposition 1, we can see that this occurs when $\kappa_{2}=0$. A sufficient condition, written in terms of the risk aversion parameter $\sigma$ is $\sigma=\sigma^{*}:=\frac{1-\gamma}{\eta(2-\gamma)}$. Denote this REE equivalence as $\mathbf{C M}\left(\sigma^{*}\right) \equiv \mathbf{C D}\left(\sigma^{*}\right)$. Perturbing the $\mathbf{I M}(\sigma)$ economy away from this special case, we have that $\partial \kappa_{2} / \partial \sigma=\eta \gamma(2-\gamma) /(1-\gamma)^{2}>0$-i.e. this implies that in the IM economies with high risk aversion at some $\sigma \neq \sigma^{*}$ (i.e. with consumer that are more sensitivity to interand intra-temporal realloaction of risky consumption), the trade-off between output gap and domestic inflation (as indexed by $\kappa_{1}$ ) will face larger "shifts" due to movements in the real exchange rate. (Also, recall the earlier observation on this point in section 3.)

Second, consider the case when $\mathbf{C M}$ is equivalent to $\mathbf{C D}$, or $\kappa^{\mathrm{CM}}=\kappa^{\mathrm{CD}}$. Comparing Proposition 1 and Proposition 2, a sufficient condition for this economy to arise is when $\sigma=\hat{\sigma}:=1 / \eta$.

\footnotetext{
${ }^{12}$ It is important to keep in mind that we are always comparing like with like-i.e. identical model parameters (for each instance of a common value for $\sigma$ ) across economies.
} 
Denote this REE equivalence as $\mathbf{C M}(\hat{\sigma}) \equiv \mathbf{C D}(\hat{\sigma})$. Away from this REE-equivalence point, the $\mathbf{C M}$ economies are such that $\partial \kappa^{C M} / \partial \sigma=(1-\gamma)^{2} /\left[(1-\gamma)^{2}+\sigma \eta \gamma(2-\gamma)\right]^{2}>0$. We summarize these intermediate observations in Lemma 1. In short, what this means is that for $\sigma>\hat{\sigma}$ away from $\mathbf{C M}(\hat{\sigma}) \equiv \mathbf{C D}(\hat{\sigma})$, a $\mathbf{C M}$ economy with higher risk aversion will face a steeper REE monetary-police trade-off between domestic inflation and output gap.

Lemma 1 Assume $\phi \searrow 0$.

- IM and CM have equivalent REE characterizations when $\sigma=\sigma^{*}:=\frac{1-\gamma}{\eta(2-\gamma)} \Rightarrow \kappa_{2}=0$. Furthermore, in the IM economy we have $\partial \kappa_{2} / \partial \sigma<0$.

- $\mathbf{C M}$ and $\mathbf{C D}$ have equivalent REE characterizations when $\sigma=\hat{\sigma}:=\frac{1}{\eta}$. Furthermore, in the $\boldsymbol{C M}$ economy, $\partial \kappa^{C M} / \partial \sigma>0$.

IM versus CM. We are now ready to show that the equilibrium policy trade-off between domestic inflation and output gap (conditional on given agents' expectations) can be steeper in IM than CM, when agents are sufficiently risk averse. First, consider the IM economy. We can equivalently derive the equilibrium relation between output gap and the real exchange rate, using the IS (3.2) and UIP (3.3) relations, as

$$
\tilde{q}_{t}=-\mu^{-1}(1-\gamma) \tilde{x}_{t}+\mu \omega(1-\gamma) \mathbb{E}_{t} \tilde{x}_{t+1}+\left[1+\mu^{-1}(1-\gamma) \chi\right] \mathbb{E}_{t} \tilde{q}_{t+1}+\mu^{-1}(1-\gamma) \epsilon_{t}+u_{t}
$$

Using (4.9) in the Phillips relation (3.1), we can equivalently write the incomplete-markets equilibrium conditional trade-off between domestic inflation and output gap as

$$
\begin{aligned}
\pi_{H, t} & =\bar{\beta} \mathbb{E}_{t} \pi_{H, t+1}+\lambda \kappa^{I M} \tilde{x}_{t}+\lambda \kappa_{2} \omega_{t}, \\
\omega_{t} & :=\mu \omega(1-\gamma) \mathbb{E}_{t} \tilde{x}_{t+1}+1-\mu^{-1}(1-\gamma) \chi \mathbb{E}_{t} \tilde{q}_{t+1}+\mu^{-1}(1-\gamma) \epsilon_{t}+u_{t},
\end{aligned}
$$

where $\kappa^{I M}=\kappa_{1}-\kappa_{2} \mu^{-1}(1-\gamma) \equiv \kappa^{C D}+\frac{\sigma \gamma}{1-\gamma}-\kappa_{2} \mu^{-1}(1-\gamma)$, and $\omega_{t}$ is another representation of the endogenous cost-push term that arises under the incomplete-markets equilibrium. In this representation we can also see that the cost push term $\omega_{t}$ not only depends on underlying shocks, but it also depends on random variables that are conditional expectations of future output and real exchange rate gaps. The first term comprising $\kappa^{I M}$ captures the direct effect of output gap on domestic inflation; the term $\kappa_{2}$ captures the direct link between the real exchange rate and domestic inflation; and the term $\mu^{-1}(1-\gamma)$ is the indirect effect of output gap, via adjustments in the ex-ante real interest rate in the IS relation, onto the real exchange rate in the UIP. 
Now compare IM with CM. There are three cases to consider. From Lemma 1, it is clear that when $\sigma=\sigma^{*}$, we have equivalent trade-offs in the two types of economies. When $\sigma>\sigma^{*}$, $\kappa_{2}<0$ and $\kappa_{2}$ is increasingly more negative with increasing $\sigma$. This implies that $\kappa^{I M}>\kappa^{C M}$. Lastly, when we have $\sigma<\sigma^{*}$, the term $\kappa_{2}$ becomes positive. However, it is ambiguous as to how these trade-offs are ordered, for arbitrary parameters. Nevertheless, we can still deduce that for $\sigma \searrow 0$ (i.e. small enough) the term $\mu^{-1} \searrow 0$ so that the trade-offs across all economies converge to the same limit of $\varphi$. This delivers us the following result which summarizes all three cases.

Proposition 3 Consider identically parameterized economies $\operatorname{IM}(\sigma)$ and $\mathbf{C M}(\sigma)$.

1. If $\sigma=\sigma^{*}$, then the two economies have identical REE trade-offs.

2. If $\sigma>\sigma^{*}$, then $\operatorname{IM}(\sigma)$ has a steeper REE inflation-output-gap trade-off than $\mathbf{C M}(\sigma)$, where:

$$
\begin{aligned}
\kappa^{I M} & =\frac{\sigma}{1-\gamma}-\kappa_{2} \mu^{-1}(1-\gamma) \\
& >\varphi+\frac{\sigma}{(1-\gamma)^{2}+\sigma \eta \gamma(2-\gamma)}=\kappa^{C M} .
\end{aligned}
$$

3. If $\sigma^{*}>\sigma \searrow 0$, then $\kappa^{I M} \rightarrow \kappa^{C D} \searrow \kappa^{C M} \searrow \varphi$.

CM versus $\mathbf{C D}$. Next, compare $\mathbf{C M}$ with $\mathbf{C D}$. Recall that a sufficient condition for $\mathbf{C M}$ to exhibit equivalent REE as CD is when $\sigma=\hat{\sigma}:=1 / \eta$, which implies that $\kappa^{C M}=\sigma+\varphi=\kappa^{C D}$.

Proposition 4 Consider identically parameterized economies $\mathbf{C M}(\sigma)$ and $\mathbf{C D}(\sigma)$.

1. If $\sigma=\hat{\sigma}$, then $\boldsymbol{C M}(\sigma)$ and $\mathbf{C D}(\sigma)$ have equivalent $R E E$.

2. If $\sigma>\hat{\sigma}$, then

$$
\begin{aligned}
\kappa^{C M} & =\varphi+\frac{\sigma}{(1-\gamma)^{2}+\sigma \eta \gamma(2-\gamma)} \\
& <\varphi+\sigma=\kappa^{C D} .
\end{aligned}
$$

3. If $\sigma<\hat{\sigma}$, then $\kappa^{C M}>\kappa^{C D}$.

Note that for empirically plausible $\eta \in(1,2)$ and $\gamma \in(0,1), \sigma^{*}<\hat{\sigma}$. This implies that the relevant range of $\sigma$ that one ought to be concerned with is given by $\sigma>\hat{\sigma}>\sigma^{*}>0$. Therefore, Propositions 3 (part 2) and 4 (part 2) are the only quantitatively relevant propositions that we will need to focus on later. These observations lead us to the following statement. ${ }^{13}$

\footnotetext{
${ }^{13}$ In general, if we introduce the possibility of imported intermediate goods on the production side, $\alpha \in(0,1)$, then an arbitrary setting of the elasticity of substitution between domestic labor and imported inputs, $v$, may switch
} 
Proposition 5 Assume the quantitatively plausible case where $\sigma>\hat{\sigma}>\sigma^{*}>0$. Then we have the following ordering of (conditional) policy trade-offs:

$$
\kappa^{I M}>\kappa^{C D}>\kappa^{C M}
$$

Explaining the policy trade-off comparisons. To summarize, if we assume a quantitatively plausible and sufficiently large risk aversion parameter $\sigma$ for agents, then in the CM economy, the conditional trade-off between domestic inflation and output gap is relatively flatter than its IM and CD counterparts. In contrast, in our IM economy, the trade-off becomes steeper relative to the same $\mathbf{C D}$ counterpart.

To explain these comparative trade-offs summarized in Propositions 3 and 4, we just need to reconsider the channels that make up $\kappa^{I M}$ in the IM economy, and those that make up $\kappa^{C M}$ and $\kappa^{C D}$, respectively.

For plausible parametrization of $\sigma>\hat{\sigma}>\sigma^{*}$, openness of the $\mathbf{C M}$ economy to trade, $\gamma \in(0,1)$, reduces $\kappa^{C M}$ relative to $\kappa^{C D}$. This is because openness under international market completeness allows the small open economy to have access to perfect cross-country insurance of its domestic fluctuations as shown in the condition (4.1). This renders the real exchange rate as a complete shock absorber for the economy so that consumption is smoothed across countries, state-by-state and date-by-date. Thus innovations to domestic output gap in $\mathbf{C M}$ has a weaker impact on domestic inflation than in $\mathrm{CD}$, since domestic agents now can borrow or lend (i.e. switch consumption expenditures) internationally in complete contingent claims markets. This was originally pointed out by Clarida et al. [2001].

What then happens with the IM economy is that while domestic agents can borrow or lend internationally to attempt to smooth out domestic fluctuations in consumption, they do not have the perfect international risk sharing present in the case of $\mathbf{C M}$. Risk sharing is only in conditional expectations terms. Hence, the UIP-type condition (3.3). This shows up in relation to domestic inflation, in reduced-form, as

$$
\kappa^{I M} \equiv \underbrace{\kappa^{C D}+\frac{\sigma \gamma}{1-\gamma}}_{\kappa_{1} \text { : domestic marginal cost channel }}+\underbrace{\left[-\kappa_{2} \mu^{-1}(1-\gamma)\right]}_{\text {incomplete risk sharing channel }}>0
$$

in (4.10) where $\mu \approx\left[\frac{1-\gamma}{\sigma}\right]\left[1-\gamma+\frac{\eta \gamma(2-\gamma)(\sigma)}{1-\gamma}\right]$. Observe that the first two terms $\kappa^{C D}+\frac{\sigma \gamma}{1-\gamma} \equiv \kappa_{1}$ is what would have been the trade-off component due purely to output gap via the domestic real marginal cost channel. In other words, these terms would capture qualitatively the same the ordering $\kappa^{C M}<\kappa^{\text {closed }}<\kappa^{I M}$. However, given the plausible parametrization, this order is still preserved. This general setting is dealt with in our Supplementary Appendix. 
explanations for the trade-off as in a purely CD economy, but one which is weakened by trade openness, $\gamma \in(0,1)$. Therefore, the last term $-\kappa_{2} \mu^{-1}(1-\gamma)$ captures the additional channel arising under international asset-market incompleteness. Recall from Section 3 , the term $\kappa_{2}$ encodes additional substitution and wealth effects on labor supply as a result of direct variations in the international real exchange rate, which in turn determine variations in domestic inflation. This term, under plausible parametrization of $\sigma>\hat{\sigma}>\sigma^{*}$ is negative, and increasingly negative with $\sigma$. The interaction of $\kappa_{2}$ with $\mu^{-1}(1-\gamma)$ summarizes the indirect effect of innovations through incomplete international risk sharing (via the domestic ex-ante real interest rate) onto domestic inflation. Specifically, note that $\mu^{-1}$ is increasing in magnitude with risk aversion $\sigma$. In words, the additional impact of incomplete markets is more severe on domestic inflation the more agents dislike large reallocations of consumption across states and dates, since the real exchange rate cannot be a complete-insurance shock absorber, unlike in the case of $\mathbf{C M}$.

Also, note that market incompleteness affects the equilibrium relation between output gap and the real interest rate, given by $\mu$ in (3.2). In the $\mathbf{C M}$ version this parameter would be $\mu^{C M}$, as defined in (4.5).

These explanations will help shed light on the implications of market incompleteness for equilibrium determinacy under alternative policy rules later.

Managing expectations and endogenous cost push. Another observation, which we will come back to later when discussing alternative policies, is that in (4.10), the endogenous costpush term $\omega_{t}$, can play a vital linkage between stabilizing policies and expectations management. The intuition works as follows. Under incomplete markets, we have an exacerbation of the contemporaneous policy trade-off as stated in Proposition 5. However, if an interest-rate policy can also "correctly" manipulate the conditional expectation terms in $\omega_{t}$, then it can alleviate this trade-off somewhat. We say "correctly" because it is not clear that a policy that directly responds to these expectational variables may be stabilizing. In fact, by doing so, it may create more inflationary expectation spirals. On the contrary, as we will illustrate later, managing these expectations indirectly by conditioning policy of past growth in the variables will turn out to be more desirable, from an equilibrium determinacy perspective.

In contrast, in the $\mathbf{C D}$ and $\mathbf{C M}$ economies, this endogenous cost-push term is non-existent. Thus, one would expect a policy that directly manipulates conditional expectations will not do better in yielding stable rational expectations equilibrium in these environments.

However, if $\phi \searrow 0$, then $\mu \approx \mu^{C M}$. Therefore, the effect of market incompleteness in the equilibrium relation between output gap and the real interest rate will be negligible. 


\section{Implications for Policy Rules and REE Determinacy}

In this section we show how the additional incomplete-asset-markets friction alters the space of alternative policy rules that can feasibly deliver a unique REE. The main conclusion here is that incomplete asset markets result in implications for REE stability under various policy rules, that are drastically different to the well-known wisdom from the closed-economy [e.g. Bullard and Mitra, 2002] and complete markets small-open-economy [e.g. Llosa and Tuesta, 2008] literature.

Unfortunately, the various REE determinacy characterizations for the IM economy cannot be derived analytically, unlike its special cases of CM [see Llosa and Tuesta, 2008] and CD [see Bullard and Mitra, 2002]. Nevertheless, we can illustrate our insights from Section 4 numerically.

Our baseline economy (IM) is parametrized in line with Llosa and Tuesta [2008]. ${ }^{14}$ Llosa and Tuesta [2008] use the same parametrization as Galí and Monacelli [2005] with the exception of the constant relative risk aversion coefficient $(\sigma)$, the inverse of Frisch labor supply elasticity $(\varphi)$, and the elasticity of substitution between domestic and foreign goods $(\eta)$. For a majority of parameters, we follow that of in Llosa and Tuesta [2008] for two reasons: (i) Ease of comparison of their findings with ours in terms of the REE stability analyses; and (ii) The setting in Llosa and Tuesta [2008] is a more general parametrization. Furthermore, these parameters does not affect qualitatively the results, although they may have important quantitative effects. This is especially true in the case of $\sigma .{ }^{15}$ We summarize the model parameters in Table 1.

Note that this set of parameters is also used for the limit economies CM and CD. That is, by using the relevant composite parameters, we have: (i) The small open economy with complete markets ("CM"): $\kappa_{2}=0, \kappa_{1}=\kappa^{C M}$ and $\mu=\mu^{C M}$; and, (ii) The closed economy ("CD"): $\gamma=0$.

\subsection{Numerical illustration of trade-offs}

As a preliminary exercise we demonstrate, for the baseline parametrization, the REE policy trade-off comparisons explained earlier in Section 4. From Table 2 we conclude the following. First, the positive trade-off between domestic inflation and output gap, given by $\lambda \kappa_{1}$, is much larger (i.e. around six times larger) with incomplete markets. The intuition for this was shown in Proposition 5 along with its discussion. In short, in the absence of complete international risk

\footnotetext{
${ }^{14}$ For the generalized version of this model, we parametrize its additional imported production input components according to McCallum and Nelson [1999].

${ }^{15}$ The goal in this paper is to understand the qualitative implications of incomplete markets on equilibrium stability using a simple but salient model, and not to quantify or match business cycle regularities. However, we do perform some sensitivity analysis in this parameter when it would be required. Results of these alternative experiments are available from the authors.
} 
Table 1: Parametrization for IM model

\begin{tabular}{lcc}
\hline \hline Parameter & Value & Source \\
\hline Risk aversion, $\sigma$ & 5 & $\mathrm{LT}$ \\
Disutility of labor, $\psi$ & 1 & $\mathrm{GM}$ \\
Inverse Frisch elasticity, $\varphi$ & 0.47 & $\mathrm{LT}$ \\
Discount factor elasticity, $\phi$ & $10^{-6}$ & \\
Steady state discount factor, $\bar{\beta}$ & 0.99 & $\mathrm{GM}$ \\
Home-Foreign goods elasticity of substitution, $\eta$ & 1.5 & $\mathrm{LT}$ \\
Share of Home goods in $C, \gamma$ & 0.4 & $\mathrm{GM}$ \\
Elasticity of substitution between good varieties, $\varepsilon$ & 6 & $\mathrm{GM}$ \\
Price stickiness probability, $\theta$ & 0.75 & $\mathrm{GM}$ \\
\hline \hline GM: Galí and Monacelli [2005]; LT: Llosa and Tuesta [2008] & & \\
$\ddagger$ In the generalized model with imported inputs there are two additional parameters \\
which we set according to McCallum and Nelson [1999]. These are the labor-imported- \\
input elasticity of substitution $(v=-2)$ and the steady-state imported-input share of out- \\
put $(\delta=0.144)$. See our Supplementary Appendix for this generalized model.
\end{tabular}

sharing, a given external shock to the small open economy cannot be fully insured against by the single incomplete market claim. Hence the effect of the shock gets amplified or transmitted more to domestic allocations via the inflation process. Second, the equivalent version of $\lambda \kappa_{1}$ in the closed economy ("CD") is between the value in the incomplete market version and the complete market version. Given that $\phi$ is very close to zero, the response of the output gap to the interest rate, given by $\mu$ is the same in the two versions of open economies. Last, the relation between the output gap and the interest rate, given by $\mu$ is much smaller in the closed economy. The reason for this is as in Galí and Monacelli [2005] - viz. trade openness presents an indirect terms of trade (or real exchange rate) variation on aggregate demand.

Table 2: Comparing REE characterizations

\begin{tabular}{lrrr}
\hline \hline & IM & CM & CD \\
\hline$\lambda \kappa_{1}$ & 0.756 & 0.124 & 0.470 \\
$\lambda \kappa_{2}$ & -1.087 & 0 & 0 \\
$\mu$ & 1.032 & 1.032 & 0.200 \\
\hline \hline
\end{tabular}

Note: This is for the baseline parametrization, where $\sigma=5$.

\subsection{Policy rules and REE (in)determinacy}

Next, we study the implications of IM for REE stability under alternative monetary-policy rules. Overall, we consider six classes of simple contemporaneous and forecast-based Taylortype monetary policy rules used in the literature [see e.g. Llosa and Tuesta, 2008; Bullard and Mitra, 2002]. These are summarized in Table 3. For the main discussion hereinafter, we will focus on the simple DITR rule, and then also discuss two other examples with the MERTR and 
Table 3: Alternative monetary policy rules

\begin{tabular}{l|ll}
\hline DITR & $r_{t}=\phi_{\pi} \pi_{H, t}+\phi_{x} \widetilde{x}_{t} ;$ & Domestic inflation targeting \\
FB-DITR & $r_{t}=\phi_{\pi} \mathbb{E}_{t}\left\{\pi_{H, t+1}\right\}+\phi_{x} \mathbb{E}_{t}\left\{\widetilde{x}_{t+1}\right\}$ & Forecast-based version of DITR \\
CPITR & $r_{t}=\phi_{\pi} \pi_{t}+\phi_{x} \widetilde{x}_{t}$ & CPI inflation targeting rule \\
FB-CPITR & $r_{t}=\phi_{\pi} \mathbb{E}_{t}\left\{\pi_{t+1}\right\}+\phi_{x} \mathbb{E}_{t}\left\{\widetilde{x}_{t+1}\right\}$ & Forecast-based CPITR \\
MERTR & $r_{t}=\phi_{\pi} \pi_{H, t}+\phi_{x} \widetilde{x}_{t}+\phi_{s} \triangle s_{t}$ & Managed exchange rate rule \\
FB-MERTR & $r_{t}=\phi_{\pi} \mathbb{E}_{t} \pi_{H, t+1}+\phi_{x} \mathbb{E}_{t} \widetilde{x}_{t+1}+\phi_{s} \mathbb{E}_{t} \triangle s_{t+1}$ & Forecast-based MERTR \\
\hline
\end{tabular}

${ }^{\dagger}$ The elasticities $\phi_{\pi}, \phi_{x}$, and, $\phi_{s}$ are non-negative policy reaction parameters. $\pi_{t}$ is the inflation rate of the CPI index. $\Delta s_{t}:=s_{t}-s_{t-1}$ denotes the growth rate in the nominal exchange rate $S_{t}$. In the paper we focus discussions on the DITR, MERTR and FB-MERTR families.

FB-MERTR family of policy rules. We consider these examples here because they are sufficient to illustrate the additional implications of our IM economy for stabilization policy. In particular, the endogenous cost-push term in the IM economy's monetary-policy trade-off was shown to depend on expectations of future variables and we conjectured that policy rules that can manage these expectations may turn out to be more robust in a REE determinacy sense. We relegate discussions on the other alternative policy rules to our Supplementary Appendix.

Where relevant, we will compare within each policy class, the REE stability and indeterminacy implications across the three economies: (a) The small open economy with complete markets ("CM") limit; (b) the closed economy limit ("CD"); and (c) the encompassing small open economy with incomplete markets model ("IM").

Given each policy rule above, and the competitive equilibrium conditions (3.1), (3.2) and (3.3), the equilibrium system can be reduced to

$$
\mathbb{E}_{t} \mathbf{x}_{t+1}=\mathbf{A} \mathbf{x}_{t}+\mathbf{C} \mathbf{w}_{t}
$$

where $\mathbf{x}:=\left(\pi_{H}, \tilde{x}, \tilde{q}\right)$, and $\mathbf{w}:=(\varepsilon, u)$; and $\mathbf{A}:=\mathbf{A}(\vec{\theta}, \vec{\phi})$ and $\mathbf{C}:=\mathbf{C}(\vec{\theta}, \vec{\phi})$ depend on the parameters in (3.1), (3.2) and (3.3), $\vec{\theta}:=\left(\bar{\beta}, \gamma, \lambda, \kappa_{1}, \kappa_{2}, \omega, \mu, \chi\right)$; and also the policy parameters $\vec{\phi}:=\left(\phi_{\pi}, \phi_{x}, \phi_{s}\right)$.

Local stability of a REE depends on the eigenvalues of matrix A. Following the terminology of Blanchard and Kahn [1980], we can see that there are three non-predetermined variables. Therefore, the equilibrium under DITR will be determinate if the three eigenvalues of A are outside the unit circle, whereas it will be indeterminate when at least one of the three eigenvalues of $\mathbf{A}$ is inside the unit circle. Unfortunately, we are not able to obtain analytical characterizations of the stability conditions for each class of policy rules. We numerically check for determinate REE (and similarly check for multiplicity of REE) as functions of the policy parameters. In particular, we consider $\phi_{\pi} \in[0,4]$ and $\phi_{x} \in[0,4]$, as in Llosa and Tuesta [2008], and vary $\phi_{s}$ where relevant. 
We will state the overall conclusions for our baseline model parametrisation. First, market incompleteness results in an opposite conclusion to the finding in Llosa and Tuesta [2008]. Llosa and Tuesta [2008] showed that the set of admissible DITR (that respond to contemporaneous variables) inducing unique REE, in a small open economy with complete markets, is larger than that in its closed-economy limit. In general, we find that market incompleteness makes the admissible policy sets smaller than when we have the limit of the complete-markets small open economy. In the specific case of the DITR, international asset market incompleteness also reduces the admissible policy space relative to when we have the closed-economy limit. Second, if the policy rules are of the forecast-based families (FB-DITR, FB-CPITR and FB-MERTR), then market incompleteness in our model also shrinks the sets of these policies that can induce unique REE, relative to their counterparts in the special case of the complete-markets small open economy model. Third, if monetary policy can be described by simple policy rules, then a contemporaneous rule (MERTR) that not only responds to domestic inflation and output gap, but also to the real exchange rate growth, can greatly expand the feasible set of such policies in inducing determinate rational expectations equilibrium. This result is also well-known in the context of small open economies with complete markets [see e.g. Llosa and Tuesta, 2008].

DITR. Figure 1 reports the simulation results for DITR across the three economies, under the baseline parametrization. Each shaded region refers to the set of DITR policy rules, indexed by $\left(\phi_{\pi}, \phi_{x}\right)$, that would have induced a determinate (i.e. stable) REE in each of the economies $\mathbf{C M}$, CD, and IM. The complement set of each shaded region represents the region with multiple or indeterminate REE.

[ Figure 1 about here. ]

Consider our baseline IM economy under the DITR family of policy rules. We observe that the largest value of $\phi_{\pi}$ for which REE indeterminacy arises is 1 which corresponds with $\phi_{x}=0$. The largest value of $\phi_{x}$ for which we find indeterminacy is 4 , which corresponds to $\phi_{\pi}=0.97$. In fact, the points $\left(\phi_{\pi}, \phi_{x}\right)=(0.97,4)$ and $\left(\phi_{\pi}, \phi_{x}\right)=(1,0)$ determine the length of the locus in Figure 1 that separates the region of DITR policies that induce REE indeterminacy (i.e. to its left) and region of DITR policies that induce REE stability (i.e. to its right).

From this figure, we can see that the monetary authority is not constrained if the policy reaction to inflation $\phi_{\pi}$ is larger than unity (i.e. the "Taylor principle"). However, provided that $\phi_{\pi}<1$, the smaller this policy parameter is, the greater the authority's response to the output gap. 
Further, from Figure 1, we can see a qualification of existing results [e.g. Llosa and Tuesta, 2008] that openness to trade reduces indeterminacy of REE under the DITR family of policy rules. Now, openness to trade under complete markets $(\mathbf{C M})$ reduces the set of DITR policy that induces REE indeterminacy, compared to the CD economy. However, incomplete asset markets (IM) expands the set of indeterminate REE from that of the CD economy. This observation is new to the literature. In other words, while trade openness reduces the constraint for DITR policy makers if markets are complete, this openness increases the constraints if markets are incomplete. However, note that the above result requires that the parametrization of the CRRA parameter $\sigma$ be "sufficiently large".

The intuition for this is not surprising once we recall our observations in Section 4.2, and in particular, Proposition 5. As discussed in Section 4.2, and also numerically verified in Table 2, market incompleteness does two things: (i) it exacerbates the slope of the inflation-outputgap trade-off; and (ii) it amplifies the shifts to this trade-off due to the endogenous cost-pushreal-exchange-rate channel. The additional sensitivity of inflation to output gap and the real exchange rate in the Phillips curve means that a DITR policy maker in the IM economy will have to counter movements in inflation much more than its counterparts in the $\mathbf{C M}$ or $\mathbf{C D}$ economies, in order to deliver a determinate REE. Finally, under CM, the trade-off is flatter than under CD. Thus the same observation as in Llosa and Tuesta [2008] applies here: That for a given response to domestic inflation, a CM-DITR policy intending to deliver a determinate or stable REE needs to respond less heavily to output gap than its counterpart one in the CD setting, provided that the expenditure switching channel is sufficiently strong, i.e. $\sigma \eta>1$.

For completeness, we also consider numerical examples where $\sigma$ is "small", and in particular, when $\sigma=\sigma^{*}$ (equivalence between IM and $\mathbf{C M}$ ) or $\sigma=\hat{\sigma}$ (equivalence between $\mathbf{C M}$ and CD). The numerical results are reported in Table 4. From Propositions 3 and 4, we can already

Table 4: Regions of DITR policies that induce REE indeterminacy_alternative cases of $\sigma$

\begin{tabular}{l|cc|cc|cc}
\hline \hline & \multicolumn{2}{|c|}{ IM } & \multicolumn{2}{c|}{ CM } & \multicolumn{2}{c}{ CD } \\
$\sigma$ & Corners $^{\dagger}\left(\phi_{\pi}, \phi_{x}\right)$ & Area $^{\ddagger}$ & Corners $^{\dagger}\left(\phi_{\pi}, \phi_{x}\right)$ & Area $^{\ddagger}$ & Corners $^{\dagger}\left(\phi_{\pi}, \phi_{x}\right)$ & Area $^{\ddagger}$ \\
\hline 5 (baseline) & $(0.99,0),(0.97,4)$ & 3.942 & $(1,0),(0.67,4)$ & 3.336 & $(1,0),(0.91,4)$ & 3.825 \\
$\hat{\sigma}=0.67$ & $(0.99,0),(0.79,4)$ & 3.580 & $(1,0),(0.59,4)$ & 3.160 & $(1,0),(0.59,4)$ & 3.160 \\
$\sigma^{*}=0.25$ & $(0.99,0),(0.47,4)$ & 2.923 & $(0.99,0),(0.47,4)$ & 2.923 & $(1,0),(0.35,4)$ & 2.673 \\
0.15 & $(0.99,0),(0.39,4)$ & 2.754 & $(0.99,0),(0.39,4)$ & 2.754 & $(1,0),(0.24,4)$ & 2.459 \\
0.1 & $(0.99,0),(0.32,4)$ & 2.614 & $(0.99,0),(0.32,4)$ & 2.614 & $(1,0),(0.18,4)$ & 2.322 \\
\hline \hline
\end{tabular}

† "Corners" refer to the two interior vertices of region of policies that yield indeterminate REE. See Figure 1 for an example of the baseline parametrization with $\sigma=5$.

$\ddagger$ "Area" refers to the area of the polygonal region of policies that yield indeterminate REE. The sample policies in the relevant region are given by the interior "corners" and the origin $(0,0)$ and $(0,4)$ in $\left(\phi_{\pi}, \phi_{x}\right)$-space.

expect the results for values of the CRRA parameter $\sigma$ that are "too small". The first row of 
Table 4 is the baseline case across all three economies-i.e. the tabulation of Figure 1. Next, consider the second row as an example, where $\sigma=\hat{\sigma}$ (equivalence between $\mathbf{C M}$ and $\mathbf{C D}$ ). This example shows that the regions of DITR policies that induce REE stability (or indeterminacy) are identical for the $\mathbf{C M}$ and $\mathbf{C D}$ economies. Moreover, the area of indeterminacy for the $\mathbf{I M}$ economy is larger. The intuition for this comes from observing that the policy trade-off in this case for IM, $\kappa_{\hat{\sigma}}^{I M}=\kappa_{\hat{\sigma}}^{C D}+\frac{\hat{\sigma} \gamma}{1-\gamma}-\kappa_{2} \mu^{-1}(1-\gamma)>\kappa_{\hat{\sigma}}^{C D} \equiv \kappa_{\hat{\sigma}}^{C M}>0$ - i.e. it is steeper than the equivalent $\mathbf{C M}$ and $\mathbf{C D}$ economies. We summarize the main finding above and its alternative numerical results from Table 4 in the following three statements.

Result 1 Assume the DITR family of monetary policy rules. Comparing $\operatorname{IM}(\sigma)$ and the $\operatorname{CM}(\sigma)$ open economies we observe that:

- If $\sigma>\sigma^{*}$ (i.e. $\left.\kappa_{2}<0\right)$ then the set of DITR policy rules indexed by $\left(\phi_{\pi}, \phi_{x}\right)$ that would have induced indeterminate (stable) REE is larger (smaller) in the IM $(\sigma)$ economy.

- If $\sigma \leq \sigma^{*}$ (i.e. $\left.\kappa_{2} \leq 0\right)$ then the set of DITR policy rules indexed by $\left(\phi_{\pi}, \phi_{x}\right)$ that would have induced indeterminate (or stable) REE is the same in $\mathbf{I M}(\sigma)$ and in $\mathbf{C M}(\sigma)$.

Result 2 Comparing the $\boldsymbol{C D}(\sigma)$ and the $\boldsymbol{C M}(\sigma)$ economies we observe that:

- If $\sigma>\hat{\sigma}$, then the set of DITR policy rules indexed by $\left(\phi_{\pi}, \phi_{x}\right)$ that would have induced indeterminate (or stable) REE is smaller (larger) in the $\mathbf{C M}(\sigma)$ economy.

- If $\sigma=\hat{\sigma}$, then the set of DITR policy rules indexed by $\left(\phi_{\pi}, \phi_{x}\right)$ that would have induced indeterminate (or stable) REE is the same in the $\mathbf{C M}(\sigma)$ economy and in the $\boldsymbol{C D}(\sigma)$ economy.

- If $\sigma<\hat{\sigma}$, then the set of DITR policy rules indexed by $\left(\phi_{\pi}, \phi_{x}\right)$ that would have induced stable (indeterminate) REE is larger (smaller) in the $\mathrm{CD}(\sigma)$ economy.

Result 3 Comparing the $\operatorname{IM}(\sigma)$ and the $\operatorname{CD}(\sigma)$ economies we observe that the set of DITR policy rules that would have induced an indeterminate (stable) REE is always larger (smaller) in the open IM economy.

These numerical results corroborate our theoretical insights from Propositions 3, 4 and 5 above. However, recall that some of these possibilities described above would be moot, from a quantitative point of view, since one typically parametrizes $\sigma \geq 1$, and for plausible calibrations, we will have $\sigma^{*}<\hat{\sigma}<\sigma<1$. 
MERTR. Consider the Managed Exchange Rate Taylor Rule (MERTR). Using the definition of the nominal exchange rate, $\Delta s_{t}=\Delta q_{t}+\pi_{t}-\pi_{t}^{*}$, where without loss of generality we set $\pi_{t}^{*}=0$, we then obtain the relation that $\Delta s_{t}=\frac{1}{1-\gamma} \Delta q_{t}+\pi_{H, t}$. Using this, we have an equivalent representation of the MERTR as

$$
r_{t}=\left(\phi_{\pi}+\phi_{s}\right) \pi_{H, t}+\phi_{x} \widetilde{x}_{t}+\left(\frac{\gamma \phi_{\pi}+\phi_{s}}{1-\gamma}\right)\left(\widetilde{q}_{t}-\widetilde{q}_{t-1}\right)
$$

By combining this rule with the equilibrium conditions for the IM economy, we can again characterize REE stability numerically.

Similarly, we can derive a representation of the MERTR for the case of the CM economy as

$$
r_{t}=\left(\phi_{\pi}+\phi_{s}\right) \pi_{H, t}+\left(\phi_{x}+\frac{\tau\left(\gamma \phi_{\pi}+\phi_{s}\right)}{1-\gamma}\right) \widetilde{x}_{t}-\frac{\tau\left(\gamma \phi_{\pi}+\phi_{s}\right)}{1-\gamma} \widetilde{x}_{t-1}
$$

where $\tau:=\frac{\sigma(1-\gamma)}{(1-\gamma)^{2}+\sigma \eta \gamma(2-\gamma)}$.

We fix $\phi_{s}=0.6$ as in Llosa and Tuesta [2008]. ${ }^{16}$ Relative to the DITR, the admissible set of the MERTR inducing determinate REE equilibrium is larger. However, relative to the $\mathbf{C M}$ economy, asset market incompleteness in the IM economy reduces this set.

[ Figure 2 about here. ]

An interesting observation about this policy is its equivalence to one that also responds to a quasi-difference in output gap growth in the $\mathbf{C M}$ economy. One can interpret this as a policy that places a limit on the speed in the domestic-inflation-output-gap trade-off. It does so by responding to a measure of output gap growth and growth in the domestic-goods price level; and it thus is able to prevent a self-fulfilling prophecy spiral in unstable inflation. This is achieved to a lesser degree by (5.2) in the IM economy, since it still faces a larger policy trade-off. However, compared to the DITR policy, now the MERTR family of policies deal with managing real exchange rate growth directly. By doing so, the policies can better regular expectations of output gap and real exchange rates. The latter expectational variables feature in the composition of the endogenous cost-push shock term $\omega_{t}$ in the policy trade-off (4.10). Thus preventing a self-prophesying spiral in these variables through the endogenous cost-push term is crucial. This point is made stronger if we contrast with the next class of policy rules that attempt to manipulate expectations directly.

\footnotetext{
${ }^{16}$ Additional sensitivity results with respect to $\phi_{s}$ are available from the authors. We show that the qualitative ordering of the sets of determinate or indeterminate equilibria are not affected by the feasible choice of this parameter.
} 
FB-MERTR. It can be shown that the FB-MERTR rule has an equivalent form of

$$
r_{t}=\left(\phi_{\pi}+\phi_{s}\right) \mathbb{E}_{t} \pi_{H, t+1}+\phi_{x} \mathbb{E}_{t} \widetilde{x}_{t+1}+\left(\frac{\gamma \phi_{\pi}+\phi_{s}}{1-\gamma}\right)\left(\mathbb{E}_{t} \widetilde{q}_{t+1}-\widetilde{q}_{t}\right)
$$

in the IM economy, and,

$$
r_{t}=\left(\phi_{\pi}+\phi_{s}\right) \mathbb{E}_{t} \pi_{H, t+1}+\left[\phi_{x}+\tau\left(\frac{\gamma \phi_{\pi}+\phi_{s}}{1-\gamma}\right)\right] \mathbb{E}_{t} \widetilde{x}_{t+1}-\tau\left(\frac{\gamma \phi_{\pi}+\phi_{s}}{1-\gamma}\right) \widetilde{x}_{t}
$$

in the $\mathbf{C M}$ economy, where $\tau:=\frac{\sigma(1-\gamma)}{(1-\gamma)^{2}+\sigma \eta \gamma(2-\gamma)}$.

Relative to $\mathbf{C M}$ economy, asset market incompleteness in the $\mathbf{I M}$ economy results in a smaller admissible set of the FB-MERTR inducing determinate REE equilibrium.

[ Figure 3 about here. ]

This example policy illustrates our intuition in Section 4.2 most starkly. Now, instead of responding to real exchange rate growth, the policy responds to expectations of real exchange rate growth, inter alia. By doing so, we can see that this family of policies is less capable of delivering stable REE. The intuition is that by responding directly to expections of future variables, this exacerbates further the already larger domestic-inflation-output-gap trade-off in the IM economy (relative to $\mathbf{C M}$ ), by causing more self-fulfilling spirals in exchange rate and inflation expectations, amplified through the endogenous cost-push term $\omega_{t}$ in (4.10).

Discussion. We have seen in the illustrations above, for a quantitatively plausible risk aversion $\sigma$, that the existence of incomplete international risk sharing results in a reduction of the sets of admissible rules inducing determinate REE, relative to when the environment is the standard complete-markets small open economy; and where relevant, relative to when the environment is the standard closed economy. However, given international asset market incompleteness, the admissible set of stabilizing policy rules can be greatly expanded by a family of simple policies that take into account contemporaneous real exchange rate growth as well. In the Supplementary Appendix, we also discuss a similar result (with similar intuitions) for the class of the CPITR rule.

These results make sense, since the additional constraints on policy in the incompletemarkets setting, arose through: (i) an exacerbated conditional trade-off between domestic inflation and output gap; and (ii) the endogenous cost-push channel. As hinted earlier in Section 4.2, the latter gave us another means of preventing self-fulfilling multiple equilibria, or worse, equilibrium instability. This other means is effected through monetary policies that can "correctly" manage expectations that affect the endogenous cost-push term. By smoothing out 
output gap and real exchange rates, it turns out that the CPITR and better yet, the MERTR policies are better at inducing a determinate rational expectations equilibrium. This is perhaps one reason why practising small-open-economy inflation targeters do worry about exchange rate management in the monetary policy designs.

\section{Concluding remarks}

In this paper, we have developed a small open economy whose monetary policy implications are no longer similar to its closed-economy counterpart. We showed, in a transparent manner, that asset market incompleteness essentially exposes the supply side of the model's equilibrium characterization to a notion of an endogenous cost-push shock. Our notion of an endogenous cost-push trade-off here is different to existing models with complete markets [c.f. Monacelli, 2005]. In our model, this is a consequence of an irreducible and explicit exchange rate equilibrium dynamic channel. Moreover, this term involves endogenous random variables that comprise conditional expectations of future output gap and real exchange rate gap. We then showed how this alters the relevant monetary-policy trade off between stabilizing domestic inflation and stabilizing output gap in an analytical and comparative way. Finally, we re-visit the lessons on equilibrium determinacy under alternative rules in a small open economy. We show that asset market incompleteness now results in opposite conclusions to the existing literature utilizing the workhorse complete markets model.

While our model is a simple and transparent illustration of the relation between international asset market incompleteness, equilibrium exchange rate irreducibility, and its implications for monetary policy trade-off and rational expectations equilibrium determinacy, it is probably too simple for normative business-cycle and welfare analysis. These questions have been addressed by larger and more quantitative models [see e.g. de Paoli, 2009b; Monacelli, 2005].

\section{References}

Benigno, Gianluca and Christoph Thoenissen, "Consumption and Real Exchange Rates with Incomplete Markets and Non-traded Goods," Journal of International Money and Finance, October 2008, 27 (6), 926-948. Cited on page(s): [4], [5], [6]

- and Pierpaolo Benigno, "Price Stability in Open Economies," Review of Economic Studies, October 2003, 70 (4), 743-764. Cited on page(s): [2], [11]

Blanchard, Olivier and Charles M. Kahn, "The Solution of Linear Difference Models under Rational Expectations," Econometrica, 1980, 48, 1305-1311. Cited on page(s): [21], [14]

Bullard, James and Kaushik Mitra, "Learning About Monetary Policy Rules," Journal of Monetary Economics, 2002, 49, 1105-1129. Cited on page(s): [4], [19], [20], [13] 
Chari, V V, Patrick J Kehoe, and Ellen R McGrattan, "Can Sticky Price Models Generate Volatile and Persistent Real Exchange Rates?," Review of Economic Studies, July 2002, 69 (3), 533-63. Cited on page(s): [4], [5]

Clarida, Richard, Jordi Galí, and Mark Gertler, "The Science of Monetary Policy: A New Keynesian Perspective," Journal of Economic Literature, December 1999, 37 (4), 1661-1707. Cited on page(s): [10], [11]

_ , _ , and _ , "Optimal Monetary Policy in Open Versus Closed Economies: An Integrated Approach," AEA Papers and Proceedings, 2001, 91 (2), 248-252. Cited on page(s): [2], [3], [8], [10], [11], [12], [13], [17], [7]

de Paoli, Bianca, "Monetary Policy and Welfare in a Small Open Economy," Journal of International Economics, 2009, 77 (1), 11-22. Cited on page(s): [11]

_ , "Monetary Policy under Alternative Asset Market Structures: The Case of a Small Open Economy," Journal of Money, Credit and Banking, October 2009, 41 (7), 1301-1330. Cited on page(s): [2], [4], [27]

Ferrero, Andrea, Mark Gertler, and Lars E. O. Svensson, "Current Account Dynamics and Monetary Policy," in Jordi Galí and Mark Gertler, eds., International Dimensions of Monetary Policy, University of Chicago Press 2010, pp. 199-244. National Bureau of Economic Research Conference Report. Cited on page(s): [6], [10], [3]

Galí, Jordi and Tommaso Monacelli, "Monetary Policy and Exchange Rate Volatility in a Small Open Economy," Review of Economic Studies, 2005, 72 (3), 707-734. Cited on page(s): [2], [3], [6], [7], [8], [10], [11], [19], [20], [4], [12]

Leitemo, Kai and Ulf Söderström, "Robust Monetary Policy in a Small Open Economy," Journal of Economic Dynamics and Control, October 2008, 32 (10), 3218-3252. Cited on page(s): [4]

Linnemann, Ludger and Andreas Schabert, "Net foreign assets, interest rate policy, and macroeconomic stability," Technical Report 54, Money Macro and Finance Research Group September 2004. Cited on page(s): [4], [6]

Llosa, Luis-Gonzalo and Vicente Tuesta, "Determinacy and Learnability of Monetary Policy Rules in Small Open Economies," Journal of Money, Credit and Banking, 2008, 40 (5), 1033-1063. Cited on page(s): [3], [4], [8], [19], [20], [21], [22], [23], [25], [11], [13], [14]

Lubik, Thomas A., "Non-stationarity and instability in small open-economy models even when they are 'closed'," Economic Quarterly, 2007, Fall, 393-412. Cited on page(s): [6]

McCallum, Bennett T. and Edward Nelson, "Nominal Income Targeting in an Open-economy Optimizing Model," Journal of Monetary Economics, 1999, 43, 553-578. Cited on page(s): [4], [5], [6], [8], [19], [20], [11]

Monacelli, Tommaso, "Monetary Policy in a Low Pass-Through Environment," Journal of Money, Credit and Banking, 2005, 37 (6), 1047-1066. Cited on page(s): [2], [11], [27]

Schmitt-Grohé, Stephanie and Martín Uribe, "Closing Small Open Economy Models," Journal of International Economics, October 2003, 61 (1), 163-185. Cited on page(s): [6]

Woodford, Michael, Interest and Prices: Foundations of a Theory of Monetary Policy, Princeton, NJ: Princeton University Press, 2003. Cited on page(s): [3], [12] 
Figure 1: Domestic inflation targeting rule (DITR) and indeterminacy regions (shaded) for three economies. Each complementary region refers to stable REE cases.

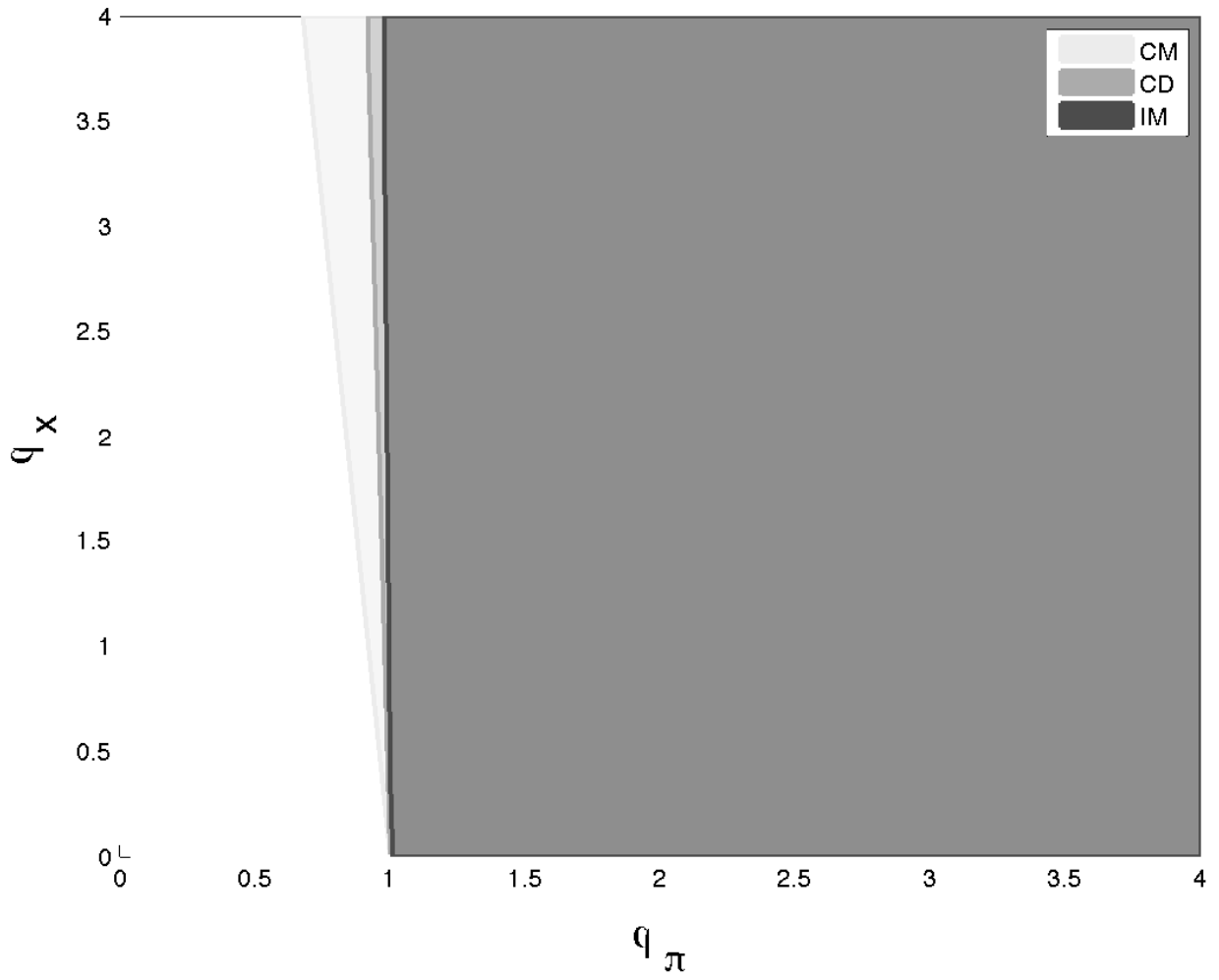


Figure 2: Managed exchange rate targeting rule (MERTR) and indeterminacy for three economies. Each complementary region refers to stable REE cases.

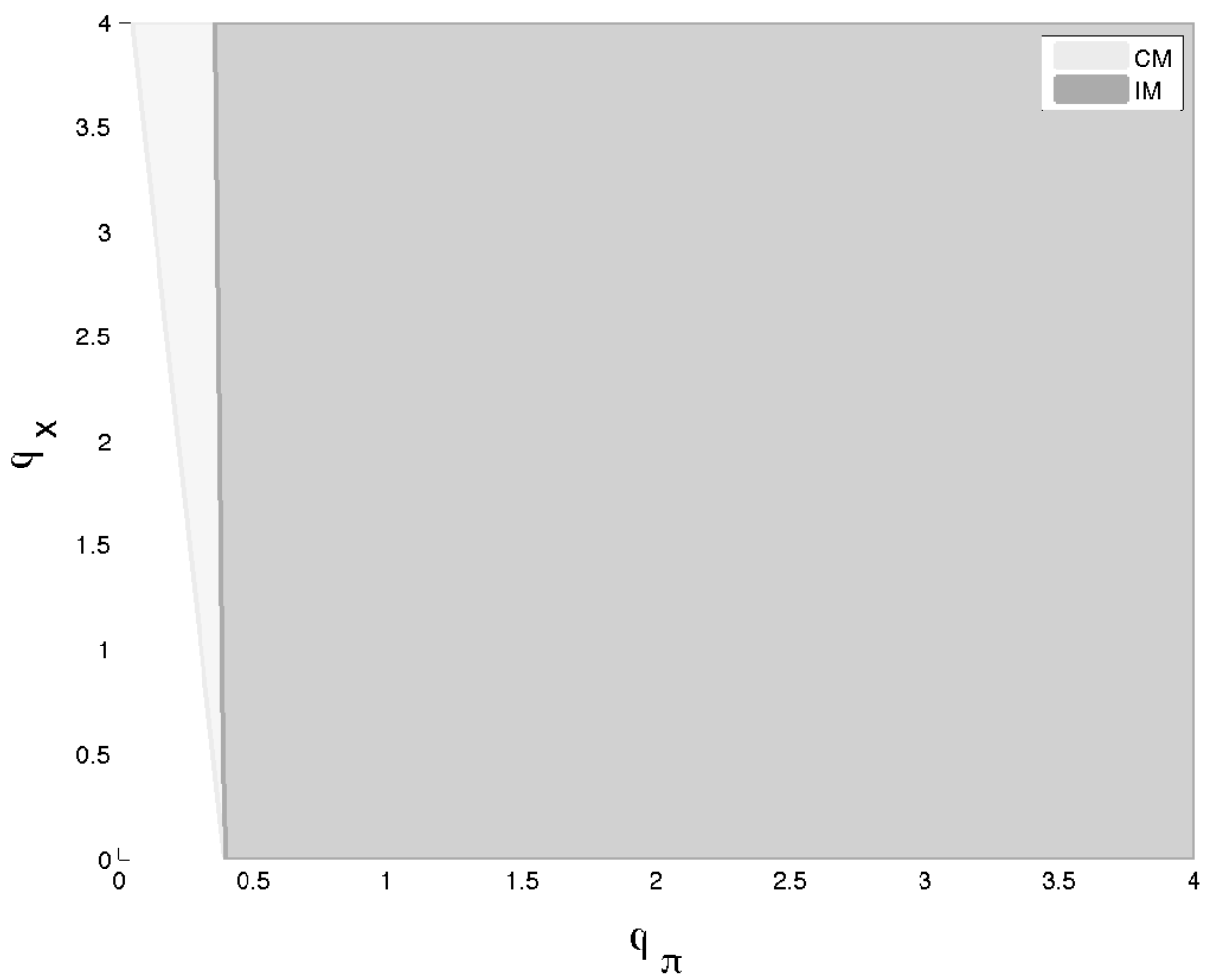


Figure 3: Forecast-based managed exchange rate targeting rule (FB-MERTR) and indeterminacy for three economies. Each complementary region refers to stable REE cases.

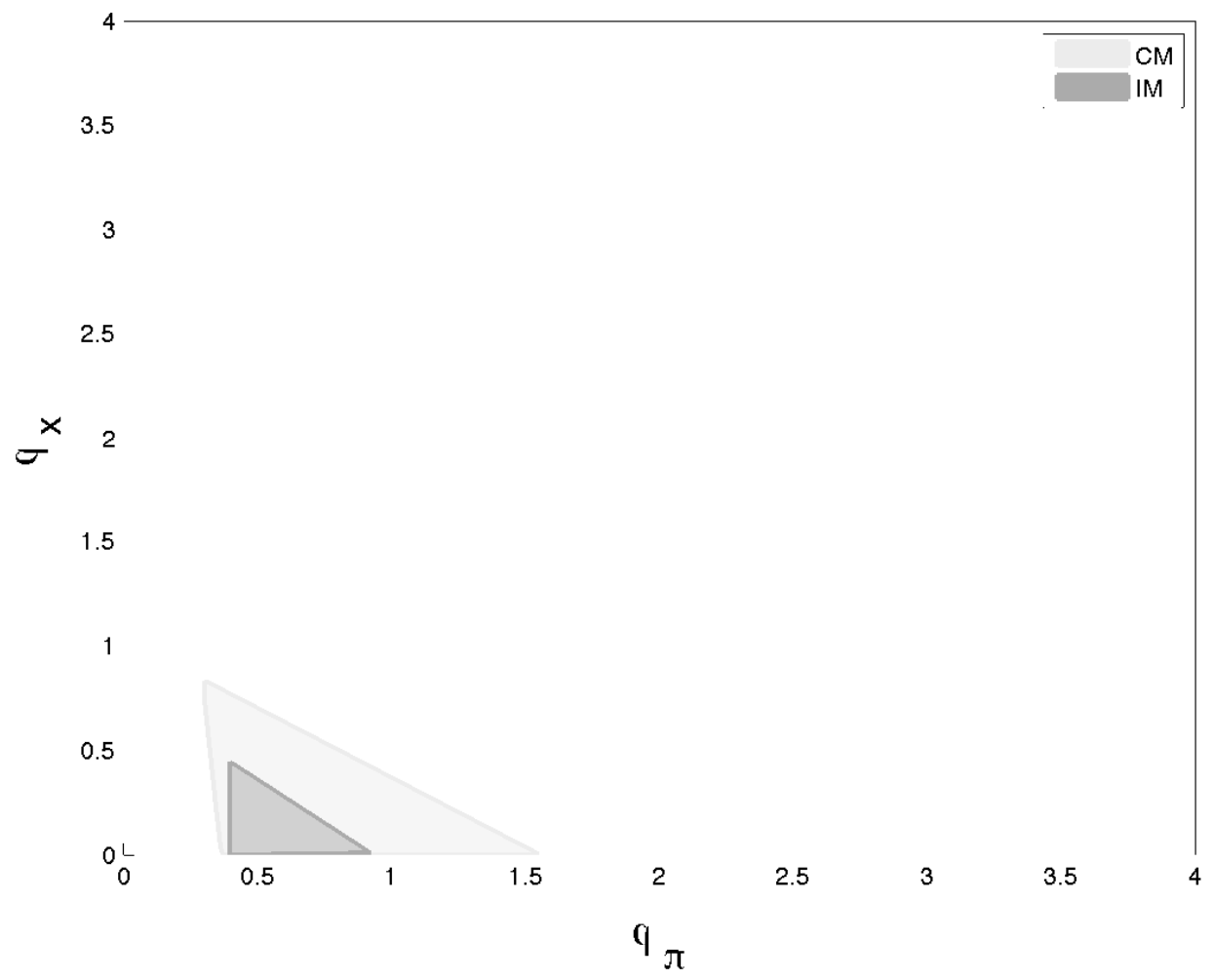


Supplementary Appendix

Anatomizing Incomplete-markets Small Open Economies: Policy Trade-offs and Equilibrium Determinacy

Jaime Alonso-Carrera $^{\dagger}$ and Timothy Kam*

Not for publication 


\section{A Derived demand and pricing functions}

Continuing from Section 2.1, recall that each optimally chosen $C_{t}$ will be consistent with the household's intra-period choice of a home-produced final consumption good, $C_{H, t}$ and an imported final good $C_{F, t}$, where $C_{t}$ is defined by a CES aggregator

$$
C_{t}=\left[(1-\gamma)^{\frac{1}{\eta}}\left(C_{H, t}\right)^{\frac{\eta-1}{\eta}}+\gamma^{\frac{1}{\eta}}\left(C_{F, t}\right)^{\frac{\eta-1}{\eta}}\right]^{\frac{\eta}{\eta-1}} ; \quad \gamma \in(0,1), \eta>1 .
$$

Each type of final good, $C_{H, t}$ and $C_{F, t}$, aggregates a variety of differentiated goods indexed by $i, j \in$ $[0,1]: C_{H, t}=\left[\int_{0}^{1} C_{H, t}(i)^{\frac{\varepsilon-1}{\varepsilon}} d i\right]^{\frac{\varepsilon}{\varepsilon-1}}$, and $C_{F, t}=\left[\int_{0}^{1} C_{F, t}(j)^{\frac{\varepsilon-1}{\varepsilon}} d j\right]^{\frac{\varepsilon}{\varepsilon-1}}$, where $\varepsilon>1$. Static expenditure minimization by consumers result in the demand functions:

$$
C_{H, t}(i)=\left(\frac{P_{H, t}(i)}{P_{H, t}}\right)^{-\varepsilon} C_{H, t}, \quad C_{F, t}(j)=\left(\frac{P_{F, t}(j)}{P_{F, t}}\right)^{-\varepsilon} C_{F, t}
$$

for all $i, j \in[0,1]$, where the aggregate price levels are solved as

$$
P_{H, t}=\left(\int_{0}^{1} P_{H, t}(i)^{1-\varepsilon} d i\right)^{\frac{1}{1-\varepsilon}}, \quad P_{F, t}=\left(\int_{0}^{1} P_{F, t}(j)^{1-\varepsilon} d j\right)^{\frac{1}{1-\varepsilon}} .
$$

Likewise, optimal consumption demand of final home and foreign goods can be derived, respectively, as

$$
C_{H, t}=(1-\gamma)\left(\frac{P_{H, t}}{P_{t}}\right)^{-\eta} C_{t}, \quad C_{F, t}=\gamma\left(\frac{P_{F, t}}{P_{t}}\right)^{-\eta} C_{t}
$$

Substitution of these demand functions into (2.7) yields the consumer price index as

$$
P_{t}=\left[(1-\gamma) P_{H, t}^{1-\eta}+\gamma P_{F, t}^{1-\eta}\right]^{\frac{1}{1-\eta}}
$$

\section{B Optimal price-setting}

We assumed in the paper a function $\mathbb{R}_{+} \ni C_{t}^{a} \mapsto \beta\left(C_{t}^{a}\right) \in(0,1)$ that represents endogenous (aggregate consumption dependent) one-period discounting. Note that for a fixed sequence of aggregate consumption $\left\{C_{\tau}^{a}\right\}_{\tau=0}^{k-1}$ the $k$-period ahead endogenous discount factor is $\prod_{\tau=0}^{k-1} \beta\left(C_{\tau}^{a}\right)$, where $\beta\left(C_{0}^{a}\right)=1$.

\section{B.1 The Calvo-style pricing problem}

The monopolistically competitive firm $i \in[0,1]$ chooses pricing strategy $\left\{P_{H, t}\left(i, h^{t}\right)\right\}$. Given Markovian public histories of states, $h^{t}:=\left\{z_{0}, \ldots, z_{t}\right\}$, we further restrict the optimal pricing strategy to belong to a class induced by stationary pricing decision functions $\tilde{P}_{H, t}$ such that $\tilde{P}_{H, t}\left(i, z_{t}\left[h^{t}\right]\right)=\tilde{P}_{H}\left(i, z_{t}\right)$.

Let the aggregate price in the home goods industry $H$, in time $t+k$ and state $z_{t+k}$, be $P_{H, t+k}\left(z_{t+k}\right):=$ $P_{H, t+k}$. The aggregate domestic and foreign consumption demands are, respectively, $C_{H, t+k}\left(z_{t+k}\right):=$ $C_{H, t+k}$ and $C_{H, t+k}^{*}\left(z_{t+k}\right):=C_{H, t+k}^{*}$. The output of firm $i$ in that state and date is then $Y_{t+k}\left(i, z_{t+k}\right):=$ 
$Y_{t+k}(i)$. The demand faced by firm $i$ in state $z_{t+k}$, if the price $\tilde{P}_{H, t}\left(i, z_{t}\right):=\tilde{P}_{H, t}(i)$ still prevails (with probability $\left.\theta^{k}\right)$ in period $t+k$ is given by

$$
Y_{t+k}(i)=\left(\frac{\tilde{P}_{H, t}(i)}{P_{H, t+k}}\right)^{-\varepsilon}\left[C_{H, t+k}+C_{H, t+k}^{*}\right]
$$

where we have suppressed the explicit state-dependence notation.

Let $\xi_{t}:=U_{C}\left[C\left(z_{t}\right)\right]$. The firm $i$ solves the following expected total discounted nominal profit maximization problem:

$$
\max _{\tilde{P}_{H, t}(i)} \sum_{k=0}^{\infty} \mathbb{E}_{t}\left\{\left(\prod_{\tau=t}^{t+k-1} \beta\left(C_{\tau}^{a}\right)\right) \frac{\xi_{t+1}}{\xi_{t}}\left[P_{H, t}(i)-M C_{t+k}^{n}\right] Y_{t+k}(i)\right\},
$$

subject to (B.1).

\section{B.2 Optimal pricing plan in a symmetric pricing equilibrium}

The first order condition with respect to $\tilde{P}_{H, t}(i)$ is

$$
\mathbb{E}_{t}\left\{\sum_{k=0}^{\infty} \theta^{k}\left(\prod_{\tau=t}^{t+k-1} \beta\left(C_{\tau}^{a}\right)\right) \frac{\xi_{t+k}}{\xi_{t}} Y_{t+k}(i)\left[\tilde{P}_{H, t}(i)-\left(\frac{\varepsilon}{\varepsilon-1}\right) M C_{t+k}^{n}\right]\right\}=0
$$

We re-write the problem in real terms, by dividing both sides of (B.3) with the aggregate home-goods price level, $P_{H, t}:{ }^{17}$

$$
\mathbb{E}_{t}\left\{\sum_{k=0}^{\infty} \theta^{k}\left(\prod_{\tau=t}^{t+k-1} \beta\left(C_{\tau}^{a}\right)\right) \frac{\xi_{t+k}}{\xi_{t}} Y_{t+k}(i)\left[\frac{\tilde{P}_{H, t}(i)}{P_{H, t}}-\left(\frac{\varepsilon}{\varepsilon-1}\right)\left(\frac{P_{H, t+k}}{P_{H, t}}\right) M C_{t+k}\right]\right\}=0 .
$$

where real marginal cost in time $t+k$ and state $z_{t+k}$ is $M C_{t+k}=: \frac{M C_{t+k}^{n}}{P_{H, t+k}}$. We restrict attention to a symmetric pricing equilibrium.

Definition 2 A symmetric pricing equilibrium is a stationary Markovian strategy such that $\left\{\tilde{P}_{H, t}\left(i, z_{t}\right)\right\}_{t=0}^{\infty}=$ $\left\{\tilde{P}_{H, t}\left(z_{t}\right)\right\}_{t=0}^{\infty}$ for all firms $i \in[0,1]$ that reset prices at time $t$, and $\left\{\tilde{P}_{H, t}\left(z_{t}\right)\right\}_{t=0}^{\infty}$ satisfies (B.4).

\section{Deriving the log-linear equilibrium system}

In this appendix we provide the details of the log-linearization of the three key conditions that locally approximate the equilibrium characterizations of recursive equilibrium in the model.

\footnotetext{
${ }^{17}$ This also renders the characterization of optimal pricing in terms of stationary variables.
} 


\section{C.1 Optimal consumer plan and UIP}

By log linearizing the previous conditions (2.4), (2.5) and (2.6), and by imposing the equilibrium condition $C_{t}=C_{t}^{a}$, we obtain that the optimal consumer's plan is approximately characterized by: ${ }^{18}$

$$
\begin{aligned}
\sigma c_{t} & =w_{t}-p_{t}-\varphi n_{t}, \\
-(\sigma-\phi) c_{t} & =r_{t}-\mathbb{E}_{t}\left\{\pi_{t+1}\right\}-\sigma \mathbb{E}_{t}\left\{c_{t+1}\right\}+\phi \vartheta \\
-(\sigma-\phi) c_{t} & =r_{t}^{*}-q_{t}+\mathbb{E}_{t}\left\{q_{t+1}\right\}-\sigma \mathbb{E}_{t}\left\{c_{t+1}\right\}+\phi \vartheta
\end{aligned}
$$

where $q_{t}$ denotes the percentage deviation from steady state of the real exchange rate $Q_{t} ; \pi_{t+1}$ is the rate of change in the domestic consumer price index from $t$ to $t+1$, i.e., $\pi_{t+1}=p_{t+1}-p_{t}$; and $r_{t}^{*}$ is the foreign interest rate, i.e., $r_{t}^{*}=i_{t}^{*}-\mathbb{E}_{t}\left\{\pi_{t+1}^{*}\right\}$, with $\pi_{t+1}^{*}$ denoting the inflation rate of the foreign consumer price index. Without loss of generality, we will assume that $r_{t}^{*}$ is just a (linear) function of $y_{t}^{*} \cdot{ }^{19}$ In order to maintain the same sign of slope of the Euler equation as in Galí and Monacelli [2005] we will require that $\sigma-\phi>0$. This requirement is consistent with our assumption, following Ferrero et al. [2010], on the subjective discount factor $(\phi \searrow 0)$ and that is has negligible qualitative and quantitative consequences on the monetary policy problem.

The log-linear form for the consumption index (2.7) is given by:

$$
c_{t}=(1-\gamma) c_{H, t}+\gamma c_{F, t}
$$

where $c_{H, t}$ is also an index of consumption of domestically produced goods; $c_{F, t}$ is an index of imported goods; and $\gamma \in[0,1]$ measures the degree of openness. The domestic consumer price index (A.3) is log-linearized as

$$
p_{t}=(1-\gamma) p_{H, t}+\gamma p_{F, t}
$$

where $p_{H, t}$ is the price index for domestically produced goods; and $p_{F, t}$ is the price index for imported goods. Similarly, domestic output in log- linear form is given in equilibrium by

$$
y_{t}=(1-\gamma) c_{H, t}+\gamma c_{H, t}^{*}
$$

where $c_{H, t}^{*}$ is the export of domestically produced goods. The optimal allocation of expenditure within

\footnotetext{
${ }^{18}$ Henceforth, lower-case letters will denote the logarithms of the corresponding upper-case variables.

${ }^{19}$ It has been shown in Galí and Monacelli [2005] that if we assume the rest of the world as a limiting closed economy under a first-best and flexible price competitive equilibrium, then $y_{t}^{*}$ is equal to its potential output. That is $y_{t}^{*}$ is approximately a linear function of its exogenous technology $a_{t}^{*}, y_{t}^{*}=b(\tilde{\theta}) a_{t}^{*}$, where $b(\tilde{\theta})$ denotes a scalar function of the closed economy's underlying taste and technology parameters $\tilde{\theta}$. Thus it suffices to characterize the approximate equilibrium solution of this model as linear functions of $\left(a_{t}, y_{t}^{*}\right)$.
} 
each category of goods yields the following demands:

$$
\begin{aligned}
c_{H, t} & =\eta\left(p_{t}-p_{H, t}\right)+c_{t}, \\
c_{F, t} & =\eta\left(p_{t}-p_{F, t}\right)+c_{t}, \\
c_{H, t}^{*} & =\eta\left(s_{t}+p_{t}^{*}-p_{H, t}\right)+c_{t}^{*} .
\end{aligned}
$$

We assumed that the law of one price holds at all periods, so that $p_{F, t}=s_{t}+p_{t}^{*}$. Combining this expression with the consumption price index (C.5) and the definition of the real exchange rate, we obtain that

$$
p_{t}-p_{H, t}=\left(\frac{\gamma}{1-\gamma}\right) q_{t}
$$

From this equation we directly follow that the rate of change in the price index of the domestically produced goods (or domestic inflation) differs from the inflation rate of the domestic consumer price index. In particular we obtain that

$$
\pi_{t}-\pi_{H, t}=\left(\frac{\gamma}{1-\gamma}\right)\left(q_{t}-q_{t-1}\right)
$$

where $\pi_{H, t}$ is the domestic inflation rate. Observe that the gap between the two inflation rates is proportional to the variation in the real exchange rate, with the degree of proportionality determined by the degree of openness $\gamma$.

By combining (C.10) with (C.6), (C.7) and (C.9), we obtain that domestic output is equal to

$$
y_{t}=(1-\gamma) c_{t}+\left[\frac{\eta \gamma(2-\gamma)}{1-\gamma}\right] q_{t}+\gamma y_{t}^{*}
$$

where we have used the fact that the foreign economy is large, which implies that the weight in the foreign composite consumption $C_{t}^{*}$ of the domestic goods is negligible, so that $y_{t}^{*}=c_{t}^{*}$.

\section{C.1.1 The UIP condition and incomplete international risk sharing}

From the optimality conditions for the consumers' problem we can derive the uncovered interest parity (UIP) condition. More specifically, from the conditions (C.2) and (C.3) we obtain the following log-linear approximation of the UIP condition:

$$
r_{t}=r_{t}^{*}+\mathbb{E}_{t}\left\{\pi_{t+1}\right\}-q_{t}+\mathbb{E}_{t}\left\{q_{t+1}\right\} .
$$

Under complete markets the Euler equations of the domestic and the foreign countries provide a tight state-by-state and date-by-date relation linking domestic consumption with foreign consumption and real exchange rate[see. e.g. Galí and Monacelli, 2005]. In particular, under our utility function (2.2) this relationship is in log-linear terms given by: $c_{t}=c_{t}^{*}+\left(\frac{1}{\sigma}\right) q_{t}$. This implies that the dynamics of output and the real exchange rate are perfectly correlated. However, this is no longer true in the case 
of incomplete asset markets. As Chari et al. [2002] show, in this case the relation between real exchange rate and consumption only holds in conditional expectation terms. In particular, combining condition (C.3) with the Euler equation of the foreign economy yields

$$
\mathbb{E}_{t}\left\{q_{t+1}\right\}-q_{t}=\left[\sigma \mathbb{E}_{t}\left\{y_{t+1}^{*}\right\}-(\sigma-\phi) y_{t}^{*}\right]-\left[\sigma \mathbb{E}_{t}\left\{c_{t+1}\right\}-(\sigma-\phi) c_{t}\right]
$$

where we have also used the condition $y_{t}^{*}=c_{t}^{*}$. Therefore, output and real exchange are not perfect correlated, so that we need equation (C.13) to characterize the full equilibrium dynamics of our model as we will show below [see also ?Benigno and Thoenissen, 2008].

Using (C.13) and (C.11), we obtain the following dynamic equation for the gap in the real exchange rate, as found in the main paper:

$$
\widetilde{q}_{t}=\mathbb{E}_{t}\left\{\widetilde{q}_{t+1}\right\}-(1-\gamma)\left[r_{t}-\mathbb{E}_{t}\left\{\pi_{H, t+1}\right\}\right]+u_{t} .
$$

\section{C.2 Approximating the supply side}

Log-linearizing (2.8) around the zero-inflation steady state, we obtain that the aggregate output in logarithmic terms is given by

$$
y_{t}=a_{t}+n_{t}
$$

Moreover, from cost minimization we obtain

$$
n_{t}=y_{t}+\left[m c_{t}-\left(w_{t}-p_{t}\right)+\left(p_{H, t}-p_{t}\right)\right]
$$

where $m c_{t}:=\ln \left(M C_{t}^{n} / P_{H, t}\right)-\ln [(1-\varepsilon) / \varepsilon]$ is the percentage deviation in real marginal cost from steady state.

\section{C.2.1 Real marginal cost}

By combining (2.9) with (C.1), (C.12), (C.15) we get

$$
m c_{t}=\left\{\left[\frac{\sigma+\varphi(1-\gamma)}{1-\gamma}\right] y_{t}+\left[\frac{\gamma}{(1-\gamma)}-\frac{\sigma \eta \gamma(2-\gamma)}{(1-\gamma)^{2}}\right] q_{t}-(1+\varphi) a_{t}-\left(\frac{\gamma(1+\varphi)}{1-\gamma}\right) y_{t}^{*}\right\}
$$

In the flexible price equilibrium, we obtain that

$$
0=\left\{\left[\frac{\sigma+\varphi(1-\gamma)}{1-\gamma}\right] \bar{y}_{t}+\left[\frac{\gamma}{(1-\gamma)}-\frac{\sigma \eta \gamma(2-\gamma)}{(1-\gamma)^{2}}\right] \bar{q}_{t}-(1+\varphi) a_{t}-\left(\frac{\gamma(1+\varphi)}{1-\gamma}\right) y_{t}^{*}\right\}(\mathrm{C}
$$


Subtracting (C.18) from (C.17) we obtain real marginal cost deviations as a function output gap and real exchange rate gap deviations:

$$
m c_{t}=\left\{\left[\frac{\sigma+\varphi(1-\gamma)}{1-\gamma}\right] \widetilde{x}_{t}+\left[\frac{\gamma}{(1-\gamma)}-\frac{\sigma \eta \gamma(2-\gamma)}{(1-\gamma)^{2}}\right] \widetilde{q}_{t}\right\} .
$$

\section{C.2.2 Optimal pricing policy function}

For small perturbations around a zero-inflation steady state, (B.4) can be approximated to first-order accuracy as:

$$
\mathbb{E}_{t}\left\{\sum_{k=0}^{\infty}\left[\beta\left(C_{s s}^{a}\right) \theta\right]^{k} \xi_{s s} Y_{s s}(i)\left[\tilde{p}_{H, t}-\ln \left(\frac{P_{H, t+k}}{P_{H, t}}\right)-m c_{t+k}\right]\right\},
$$

where

$$
\tilde{p}_{H, t}:=\ln \left(\frac{\tilde{P}_{H, t}}{P_{H, t}}\right), \quad m c_{t}:=\ln \left(\frac{M C_{t}^{n}}{P_{H, t}}\right)-\ln \left(\frac{\varepsilon-1}{\varepsilon}\right)
$$

Define $\hat{P}_{H, t}=\ln \left(P_{H, t} / P_{H, s s}\right)$. So then (C.20) can be re-written as

$$
\begin{gathered}
\left(\frac{1}{1-\beta\left(C_{S S}^{a}\right) \theta}\right) \tilde{p}_{H, t}=\mathbb{E}_{t} \sum_{k=0}^{\infty}\left[\beta\left(C_{s S}^{a}\right) \theta\right]^{k}\left[\hat{P}_{H, t+k}+m c_{t+k}\right]-\left(\frac{1}{1-\beta\left(C_{S S}^{a}\right) \theta}\right) \hat{P}_{H, t} \\
\Rightarrow \tilde{p}_{H, t}+\hat{P}_{H, t}=\left(1-\beta\left(C_{s S}^{a}\right) \theta\right) \mathbb{E}_{t} \sum_{k=0}^{\infty}\left[\beta\left(C_{s S}^{a}\right) \theta\right]^{k}\left[\hat{P}_{H, t+k}+m c_{t+k}\right] .
\end{gathered}
$$

By the law of iterated expectations, this can be written recursively as

$$
\begin{gathered}
\tilde{p}_{H, t}+\hat{P}_{H, t}=\left[1-\beta\left(C_{s s}^{a}\right)\right]\left(\hat{P}_{H, t}+m c_{t}\right)+\left[\beta\left(C_{s s}^{a}\right) \theta\right] \mathbb{E}_{t}\left(\tilde{p}_{H, t+1}+\hat{P}_{H, t+1}\right) \\
\Rightarrow \tilde{p}_{H, t}=\left[1-\beta\left(C_{s s}^{a}\right) \theta\right] m c_{t}+\left[\beta\left(C_{s S}^{a}\right) \theta\right] \mathbb{E}_{t}\left(\tilde{p}_{H, t+1}+\pi_{H, t+1}\right) .
\end{gathered}
$$

Recall that in the ?-style model, by the law of large numbers, the evolution of the aggregate home goods price level is such that

$$
P_{H, t}^{1-\varepsilon}=(1-\theta) \tilde{P}_{H, t}^{1-\varepsilon}+\theta P_{H, t-1}^{1-\varepsilon}
$$

A log-linear approximation of this yields a linear relationship between home goods price inflation, $\pi_{H, t}:=\ln \left(P_{H, t} / P_{H, t-1}\right)$ and the percentage deviation of the optimal price from the aggregate price level:

$$
\pi_{H, t}=\frac{1-\theta}{\theta} \tilde{p}_{H, t}
$$


Using this identity, and the one-period ahead forecast of the same identity, in (C.21), we obtain the characterization of the approximately log-linear optimal pricing function $\tilde{p}_{H, t}$ in terms of a forwardlooking Phillips curve:

$$
\pi_{H, t}=\bar{\beta} \mathbb{E}_{t}\left\{\pi_{H, t+1}\right\}+\left[\frac{(1-\theta)(1-\theta \bar{\beta})}{\theta}\right] m c_{t},
$$

with $\bar{\beta}:=\beta\left(C_{s s}\right)$, where $C_{s s}$ is the level of domestic consumption at the zero-inflation steady state. Combining (C.22) with (C.19), we obtain

$$
\pi_{H, t}=\bar{\beta} \mathbb{E}_{t}\left\{\pi_{H, t+1}\right\}+\lambda\left(\kappa_{1} \widetilde{x}_{t}+\kappa_{2} \widetilde{q}_{t}\right),
$$

where

$$
\begin{aligned}
& \lambda=\left[\frac{(1-\theta)(1-\theta \bar{\beta})}{\theta}\right], \\
& \kappa_{1}=\varphi+\frac{\sigma}{1-\gamma}, \quad \kappa_{2}=-\frac{\sigma \eta \gamma(2-\gamma)}{(1-\gamma)^{2}}+\frac{\gamma}{(1-\gamma)} .
\end{aligned}
$$

Equation (3.1) is almost identical, to first-order accuracy, to the Phillips curve derived in models such as Galí and Monacelli [2005] and Clarida et al. [2001]. What is different is that the one-period discount factor at the deterministic steady state is now a function of fundamental outcomes in the steady-state competitive equilibrium. In this case, it will be a function of steady-state aggregate consumption, $C_{s s}$. More generally, if we do not focus on local linearized dynamics around the deterministic steady state, the global dynamics of inflation will also depend non-linearly on the endogenous discount factor function $\beta: \mathbb{R}_{+} \rightarrow(0,1)$.

As in the closed economy a change in the domestic output has a positive effect on the domestic inflation rate. In our model the size of this effect depends on the degree of openness $\gamma$ and on the productive dependence $\alpha$ (or, equivalently, $\delta$ ). An increase in the domestic output has an effect on the marginal cost through: (i) an increase in the equilibrium level of employment, that is captured by the first term $\varphi$ in $\kappa_{1}$; (ii) a rise in the terms of trade given by the second term in $\kappa_{1}$, which is negatively related with the degree of opennes $\gamma$; and (iii) an increase in the equilibrium level of the imported intermediate good given by the second term in $\lambda$, which is positively related with the productive dependence $\alpha$ (or, equivalently, $\delta$ ). 


\section{C.3 Approximating the demand side}

By combining (C.2) with (C.11) and (C.12), we obtain after some simple algebra that

$$
\begin{aligned}
y_{t}= & \left(\frac{\sigma}{\sigma-\phi}\right) \mathbb{E}_{t}\left\{y_{t+1}\right\}-\left(\frac{1-\gamma}{\sigma-\phi}\right)\left[i_{t}-\mathbb{E}_{t}\left\{\pi_{H, t+1}\right\}\right] \\
& +\left[\frac{\gamma}{\sigma-\phi}-\frac{\sigma \eta \gamma(2-\gamma)}{(1-\gamma)(\sigma-\phi)}\right] \mathbb{E}_{t}\left\{q_{t+1}\right\} \\
& -\left[\frac{\gamma}{\sigma-\phi}-\frac{\eta \gamma(2-\gamma)}{1-\gamma}\right] q_{t}-\left(\frac{\sigma \gamma}{\sigma-\phi}\right) \mathbb{E}_{t}\left\{y_{t+1}^{*}\right\}+\gamma y_{t}^{*} \\
& -\frac{\phi \vartheta(1-\gamma)}{\sigma-\phi}
\end{aligned}
$$

\section{C.4 Potential output and real exchange rate derivations}

Here, we show that the potential output $\bar{y}_{t}$ and real exchange rate $\bar{q}_{t}$ are affine functions of exogenous random technology and foreign output, respectively, $a_{t}$ and $y_{t}^{*}$.

We first charaterize the equilibrium when prices are fully flexible, i.e., $m c_{t}=0$. From (C.1), (C.15), and (2.9),we obtain that the equilibrium with flexible prices

$$
\sigma \bar{c}_{t}+\varphi \bar{y}_{t}+\left[\frac{\gamma}{1-\gamma}\right] \bar{q}_{t}-(1+\varphi) a_{t}=0
$$

Moreover, combining the last equation with (C.12), we also obtain

$$
\bar{c}_{t}=\Omega_{1} a_{t}-\Omega_{2} \bar{q}_{t}-\Omega_{3} y_{t}^{*}
$$

where

$$
\begin{aligned}
& \Omega_{1}=\frac{1+\varphi}{\sigma+\varphi(1-\gamma)} \\
& \Omega_{2}=\left[\frac{1}{\sigma+\varphi(1-\gamma)}\right]
\end{aligned}
$$

and

$$
\Omega_{3}=\frac{\gamma \varphi}{\sigma+\varphi(1-\gamma)}
$$

Using (C.25) and (C.14), we derive that

$$
\begin{aligned}
\bar{q}_{t}= & {\left[\frac{\left(1-\sigma \Omega_{2}\right)}{1-(\sigma-\phi) \Omega_{2}}\right] \mathbb{E}_{t}\left\{\bar{q}_{t+1}\right\} } \\
& +\left[\frac{\Omega_{1}}{1-(\sigma-\phi) \Omega_{2}}\right]\left[\sigma \mathbb{E}_{t}\left\{a_{t+1}\right\}-(\sigma-\phi) a_{t}\right] \\
& -\left[\frac{1+\Omega_{3}}{1-(\sigma-\phi) \Omega_{2}}\right]\left[\sigma \mathbb{E}_{t}\left\{y_{t+1}^{*}\right\}-(\sigma-\phi) y_{t}^{*}\right]
\end{aligned}
$$

Hence, by solving forward the previous dynamic equation, we can see that the level of $\bar{q}_{t}$ at the frictionless equilibrium only depends on the exogenous stochastic variables $a_{t}$ and $y_{t}^{*}$. From (C.24) and (C.25) 
we check that the previous conclusion is also true for the case of the levels of $\bar{y}_{t}$ and $\bar{c}_{t}$.

From (C.18) and (C.23) we can derive the following condition on the equilibrium with flexible prices:

$$
\begin{aligned}
\bar{y}_{t}= & \left(\frac{\sigma}{\sigma-\phi}\right) E_{t}\left\{\bar{y}_{t+1}\right\} \\
& -\left[\frac{1-\gamma}{\sigma+\varphi(1-\gamma)}\right]\left[\frac{\gamma}{(1-\gamma)}-\frac{\sigma \eta \gamma(2-\gamma)}{(1-\gamma)^{2}}\right] \bar{q}_{t} \\
+ & {\left[\frac{\sigma(1-\gamma)}{(\sigma-\phi)[\sigma+\varphi(1-\gamma)]}\right] } \\
& \times\left[\frac{\gamma}{(1-\gamma)}-\frac{\sigma \eta \gamma(2-\gamma)}{(1-\gamma)^{2}}\right] E_{t}\left\{\bar{q}_{t+1}\right\} \\
+ & {\left[\frac{(1-\gamma)(1+\varphi)}{\sigma+\varphi(1-\gamma)}\right] a_{t}-\left[\frac{\sigma(1-\gamma)(1+\varphi)}{(\sigma-\phi)[\sigma+\varphi(1-\gamma)]}\right] E_{t}\left\{a_{t+1}\right\} } \\
+ & {\left[\frac{\sigma \gamma}{\sigma+\varphi(1-\gamma)}\right] y_{t}^{*}-\left[\frac{\gamma \sigma^{2}}{(\sigma-\phi)[\sigma+\varphi(1-\gamma)]}\right] E_{t}\left\{y_{t+1}^{*}\right\} }
\end{aligned}
$$

It is straightforward to deduce that $\bar{y}_{t}$ will just be a linear function in $\left(a_{t}, y_{t}^{*}\right)$.

\section{C.5 Deriving the output gap IS relation}

Subtracting (C.26) from (C.23), we obtain

$$
\begin{aligned}
\widetilde{x}_{t}= & \left(\frac{\sigma}{\sigma-\phi}\right) \mathbb{E}_{t}\left\{\widetilde{x}_{t+1}\right\}-\left[\frac{\gamma}{\sigma-\phi}-\frac{\eta \gamma(2-\gamma)}{1-\gamma}\right] \widetilde{q}_{t} \\
& +\left[\frac{\gamma}{\sigma-\phi}-\frac{\sigma \eta \gamma(2-\gamma)}{(1-\gamma)(\sigma-\phi)}\right] \mathbb{E}_{t}\left\{\widetilde{q}_{t+1}\right\} \\
& -\left(\frac{1-\gamma}{\sigma-\phi}\right)\left[i_{t}-\mathbb{E}_{t}\left\{\pi_{H, t+1}\right\}\right]+\xi_{t},
\end{aligned}
$$

with

$$
\begin{aligned}
\xi_{t}= & {\left[\frac{\eta \gamma \varphi(2-\gamma)}{\sigma+\varphi(1-\gamma)}+\left(\frac{1-\gamma}{\sigma+\varphi(1-\gamma)}\right) \frac{\gamma}{(1-\gamma)}-\frac{\gamma}{\sigma-\phi}\right] \bar{q}_{t} } \\
& +\left[\frac{\gamma}{\sigma-\phi}-\frac{\sigma \eta \gamma \varphi(2-\gamma)}{(\sigma-\phi)[\sigma+\varphi(1-\gamma)]}\right. \\
& \left.\quad-\left(\frac{\sigma}{\sigma-\phi}\right)\left(\frac{1-\gamma}{\sigma+\varphi(1-\gamma)}\right) \frac{\gamma}{(1-\gamma)}\right] \mathbb{E}_{t}\left\{\bar{q}_{t+1}\right\} \\
- & {\left[\frac{(1-\gamma)(1+\varphi)}{\sigma+\varphi(1-\gamma)}\right] a_{t}+\left[\frac{\sigma(1-\gamma)(1+\varphi)}{(\sigma-\phi)[\sigma+\varphi(1-\gamma)]}\right] \mathbb{E}_{t}\left\{a_{t+1}\right\} } \\
- & {\left[\frac{\gamma \varphi(1-\gamma)}{\sigma+\varphi(1-\gamma)}\right] y_{t}^{*}+\left[\frac{\gamma \sigma \varphi(1-\gamma)}{(\sigma-\phi)[\sigma+\varphi(1-\gamma)]}\right] \mathbb{E}_{t}\left\{y_{t+1}^{*}\right\}-\frac{\phi \vartheta(1-\gamma)}{\sigma-\phi}, }
\end{aligned}
$$

where $\xi_{t}$ is a stochastic, exogenous variable as can be followed from the previous characterization of the frictionless equilibrium. Finally, by introducing (3.3) into (C.27), we directly obtain equation (3.2) in the main text, where

$$
\epsilon_{t}=\xi_{t}-\left[\frac{\gamma}{\sigma-\phi}-\frac{\eta \gamma(2-\gamma)}{1-\gamma}\right] u_{t} .
$$




\section{Generalized IM Model}

Consider a generalized version of the IM model. Now, the only addition is that each domestic firm $i \in[0,1]$ produces a differentiated good using a CES technology

$$
Y_{t}\left(i, h^{t}\right)=\left\{\alpha\left[A_{t} N_{t}^{d}\left(i, h^{t}\right)\right]^{v}+(1-\alpha)\left[I M_{t}\left(i, h^{t}\right)\right]^{v}\right\}^{\frac{1}{v}} ; \alpha \in(0,1],-\infty \leq v \leq 1,
$$

where $N_{t}^{d}\left(i, h^{t}\right)$ is labor hired by the firm; and $I M_{t}(i)$ is an index of imported intermediate goods. ${ }^{20}$ the random variable $A_{t}:=\exp \left\{a_{t}\right\}$ is an exogenous embodied labor productivity.

The production cost-minimization problem for the firm is:

$$
\min P_{t}\left(h^{t}\right)\left\{Q_{t}\left(h^{t}\right) I M_{t}\left(i, h^{t}\right)+\frac{W_{t}\left(h^{t}\right)}{P_{t}\left(h^{t}\right)} N_{t}^{d}\left(i, h^{t}\right)\right\} .
$$

subject to (2.8). The first-order conditions with respect to optimal labor and intermediate-imports are

$$
\frac{W_{t}\left(h^{t}\right)}{P_{t}\left(h^{t}\right)}=\alpha \frac{M C_{t}^{n}\left(h^{t}\right)}{P_{t}\left(h^{t}\right)} A_{t}^{v}\left(\frac{Y_{t}\left(h^{t}\right)\left(i, h^{t}\right)}{N_{t}^{d}\left(i, h^{t}\right)}\right)^{1-v},
$$

and

$$
Q_{t}\left(h^{t}\right)=(1-\alpha) \frac{M C_{t}^{n}\left(h^{t}\right)}{P_{t}\left(h^{t}\right)}\left(\frac{Y_{t}\left(i, h^{t}\right)}{I M_{t}\left(i, h^{t}\right)}\right)^{1-v},
$$

respectively, where $M C_{t}^{n}$ is nominal marginal cost.

With a homogeneous of degree one production function the first-order conditions (for cost minimization with respect to labor) can be written in the aggregate as

$$
\frac{W_{t}\left(h^{t}\right)}{P_{t}\left(h^{t}\right)}=\alpha \frac{M C_{t}^{n}\left(h^{t}\right)}{P_{t}\left(h^{t}\right)} A_{t}^{v}\left(\frac{Y_{t}\left(h^{t}\right)}{N_{t}^{d}\left(h^{t}\right)}\right)^{1-v}
$$

and

$$
Q_{t}\left(h^{t}\right)=(1-\alpha) \frac{M C_{t}^{n}\left(h^{t}\right)}{P_{t}\left(h^{t}\right)}\left(\frac{Y_{t}\left(h^{t}\right)}{I M_{t}\left(h^{t}\right)}\right)^{1-v},
$$

where $M C_{t}^{n}$ is nominal marginal cost.

After some derivations, it can be shown that the REE for this economy is summarized by the following definition.

Definition 3 (General Incomplete Markets (IM)) Given a monetary policy process $\left\{r_{t}\right\}_{t \in \mathbb{N}}$ and exogenous processes $\left\{\epsilon_{t}, u_{t}\right\}_{t \in \mathbb{N}}$ a (locally approximate) rational expectations competitive equilibrium (REE) in the IM

\footnotetext{
${ }^{20}$ This intermediate good can be interpreted as two equivalent forms. On the one hand, we can assume that the imported goods can be either devoted to consumption $C_{F, t}$ or used as a production input $I M_{t}$. On the other hand, we can assume that the domestic economy imports two differentiated goods: consumption goods $C_{F, t}$ and intermediated goods $I M_{t}$.
} 
model is a bounded stochastic process $\left\{\pi_{H, t}, \widetilde{x}_{t}, \widetilde{q}_{t}\right\}_{t \in \mathbb{N}}$ satisfying:

$$
\begin{aligned}
\pi_{H, t} & =\bar{\beta} \mathbb{E}_{t}\left\{\pi_{H, t+1}\right\}+\lambda\left(\kappa_{1} \widetilde{x}_{t}+\kappa_{2} \widetilde{q}_{t}\right), \\
\widetilde{x}_{t} & =\omega \mathbb{E}_{t}\left\{\widetilde{x}_{t+1}\right\}-\mu\left[r_{t}-\mathbb{E}_{t}\left\{\pi_{H, t+1}\right\}\right]+\chi \mathbb{E}_{t}\left\{\widetilde{q}_{t+1}\right\}+\epsilon_{t}, \\
\widetilde{q}_{t} & =\mathbb{E}_{t}\left\{\widetilde{q}_{t+1}\right\}-(1-\gamma)\left[r_{t}-\mathbb{E}_{t}\left\{\pi_{H, t+1}\right\}\right]+u_{t} .
\end{aligned}
$$

where $\bar{\beta}=\beta\left(C_{s s}\right)$,

$$
\begin{aligned}
& \lambda=\frac{(1-v)(1-\delta)}{1-v+\delta \varphi}\left[\frac{(1-\theta)(1-\theta \bar{\beta})}{\theta}\right], \\
& \kappa_{1}=\varphi+\frac{\sigma}{1-\gamma}, \quad \kappa_{2}=\frac{\delta(1-v+\varphi)}{(1-\gamma)(1-v)(1-\delta)}-\frac{\sigma \eta \gamma(2-\gamma)}{(1-\gamma)^{2}}+\frac{\gamma}{(1-\gamma)} ; \\
& \omega=\frac{\sigma}{\sigma-\phi^{\prime}}, \quad \mu=\left[\frac{1-\gamma}{\sigma-\phi}\right]\left[1-\gamma+\frac{\eta \gamma(2-\gamma)(\sigma-\phi)}{1-\gamma}\right], \quad \text { and }, \quad \chi=\frac{\eta \gamma \phi(2-\gamma)}{(1-\gamma)(\sigma-\phi)} ;
\end{aligned}
$$

where $\delta=(1-\alpha)\left(I M_{s s} / Y_{S s}\right)^{v}$, with $I M_{s S}$ and $Y_{s s}$ as the stationary values of imported intermediate good and aggregate output, respectively.

\section{D.1 Parameters in the general IM model}

The generalized IM economy is parametrized in line with Llosa and Tuesta [2008] and McCallum and Nelson [1999]. Llosa and Tuesta [2008] use the same parametrization as Galí and Monacelli [2005] with the exception of the constant relative risk aversion coefficient $(\sigma)$, the inverse of Frisch labor supply elasticity $(\varphi)$, and the elasticity of substitution between domestic and foreign goods $(\eta)$. For a majority of parameters, we follow that of in Llosa and Tuesta [2008] for two reasons: (i) Ease of comparison of their findings with ours in terms of the REE stability analyses; and (ii) The setting in Llosa and Tuesta [2008] is a more general parametrization. Furthermore, these parameters does not affect qualitatively the results, although they may have important quantitative effects. This is especially true in the case of $\sigma \cdot{ }^{21}$ The parameter $v$ is from McCallum and Nelson [1999]. We summarize the model parameters in Table 1.

\section{[ Table 1 about here. ]}

Note that this set of parameters is later used to consider the limits of our model. That is, by using the relevant composite parameters, we have: (i) The small open economy with complete markets ("CM"): $\kappa_{2}=0, \kappa_{1}=\kappa_{1}^{c}$ and $\mu=\mu^{c}$; and, (ii) The closed economy ("CD”): $\gamma=0$ and $\alpha=1$ (i.e., $\delta=0$ ).

\footnotetext{
${ }^{21}$ The goal in this paper is to understand the qualitative implications of incomplete markets on equilibrium stability using a simple but salient model, and not to quantify or match business cycle regularities. However, we do perform some sensitivity analysis in this parameter when it would be required. Results of these alternative experiments will be readily made available upon request.
} 


\section{D.2 Numerical values of equilibrium relations}

By using our baseline parametrization we can now sign the reduced-form parameters in the equilibrium relations between variables in the approximation of the competitive equilibrium (3.1), (3.2) and (3.3). We report this in Table 5 .

\section{[ Table 5 about here. ]}

Recall that the only unclear equilibrium relation (in terms of sign or direction) is the slope of output gap with respect to the real exchange rate in the Phillips curve (3.1), given by $\lambda \kappa_{2}$. From a MundellFleming-type intuition, one should expect that without imported inputs this value should be negative. We show that in our baseline economy, this value is also negative with imported inputs. In fact, we obtain that $\kappa_{2}$ is positive if and only if $v \in(0.92337,1)$. Therefore, the aforementioned income effects of the exchange rate variations dominates.

At this point, it is convenient to enumerate the differences between the incomplete market version and the complete market version in terms of equilibrium relations. Remember that these differences are in the relations $\lambda \kappa_{1}, \lambda \kappa_{2}$ and $\mu$. Table 2 reports the differences across the economies with and without openness in production, and with and without market incompleteness.

[ Table 6 about here. ]

From Table 2 we conclude the following. First, the positive trade-off between domestic inflation and output gap, given by $\lambda \kappa_{1}$, is much larger (i.e. around six times larger) with incomplete markets, regardless of the presence of an imported intermediate input channel (indexed by $\delta$ ). The intuition is quite standard. In the absence of complete international risk sharing, a given external shock to the small open economy cannot be fully insured against by the single incomplete market claim. Hence the effect of the shock gets amplified or transmitted more to domestic allocations via the inflation process.

Second, the relationship between domestic-goods inflation rate and output gap, given by $\lambda \kappa_{1}$, is decreasing with $\delta$ (openness in production). Observe the Phillips curve relation in (3.1). Since there is some substitutability in the inputs in the production technology, more reliance (i.e. higher $\delta$ ) on the imported intermediate input means a substitution away from the labor input, such that all else equal, the effect of the labor cost channel on the inflation-real marginal-cost channel via $\lambda \kappa_{1}$ is then smaller.

Third, the relationship between domestic-goods inflation rate and output gap, given by $\lambda \kappa_{1}$, in the closed economy ("CD") is between the value in the incomplete market version and the complete market version.

Fourth, the openness in production, given by $\delta$, reduces the negative effect of the depreciation of the exchange rate on the inflation rate, given by $\lambda \kappa_{2}$. This is obvious because with $\delta=0$, the production effect determining $\kappa_{2}$ disappears.

Fifth, given that $\phi$ is very close to zero, the response of the output gap to the interest rate, given by $\mu$ is the same in the two versions of open economies. Last, the response of the output gap to the interest rate, given by $\mu$ is much smaller in the closed economy. The reason for this is as in Galí and Monacelli 
[2005] - viz. trade openness presents an indirect terms of trade (or real exchange rate) variation on aggregate demand.

\section{D.3 Implications for Instrument Rules and Determinacy}

Overall we consider six classes of simple contemporaneous and forecast-based Taylor-type monetary policy rules used in the literature [see e.g. Llosa and Tuesta, 2008; Bullard and Mitra, 2002].

(i) the domestic (producer price) inflation targeting rule (DITR):

$$
r_{t}=\phi_{\pi} \pi_{H, t}+\phi_{x} \widetilde{x}_{t} ;
$$

(ii) a forecast-based version of the DITR (or FB-DITR):

$$
r_{t}=\phi_{\pi} \mathbb{E}_{t}\left\{\pi_{H, t+1}\right\}+\phi_{x} \mathbb{E}_{t}\left\{\widetilde{x}_{t+1}\right\} ;
$$

(iii) the consumer price index inflation targeting rule (CPITR):

$$
r_{t}=\phi_{\pi} \pi_{t}+\phi_{x} \widetilde{x}_{t}
$$

(iv) a forecast-based CPITR (or FB-CPITR):

$$
r_{t}=\phi_{\pi} \mathbb{E}_{t}\left\{\pi_{t+1}\right\}+\phi_{x} \mathbb{E}_{t}\left\{\widetilde{x}_{t+1}\right\} ;
$$

(v) the managed exchange rate targeting rule (MERTR):

$$
r_{t}=\phi_{\pi} \pi_{H, t}+\phi_{x} \widetilde{x}_{t}+\phi_{s} \triangle s_{t}
$$

(vi) a forecast-based MERTR (FB-MERTR):

$$
r_{t}=\phi_{\pi} \mathbb{E}_{t} \pi_{H, t+1}+\phi_{x} \mathbb{E}_{t} \widetilde{x}_{t+1}+\phi_{s} \mathbb{E}_{t} \triangle s_{t+1},
$$

where the elasticities $\phi_{\pi}, \phi_{x}$, and, $\phi_{s}$ are non-negative reaction parameters. In the paper, we discussed rules (i) DITR, (v) MERTR, and (vi) FB-MERTR. We present and discuss the other cases here in this appendix.

Where relevant, we will compare within each policy class, the REE stability and indeterminacy implications across the three economies: (a) The small open economy with complete markets ("CM") limit; (b) the closed economy limit ("CD"); and (c) the encompassing small open economy with incomplete markets model ("IM"). 
Given each policy rule above, and the competitive equilibrium conditions (3.1), (3.2) and (3.3), the equilibrium system can be reduced to

$$
\mathbb{E}_{t} \mathbf{x}_{t+1}=\mathbf{A} \mathbf{x}_{t}+\mathbf{C} \mathbf{w}_{t}
$$

where $\mathbf{x}:=\left(\pi_{H}, \tilde{x}, \tilde{q}\right)$, and $\mathbf{w}:=(\varepsilon, u) ;$ and $\mathbf{A}:=\mathbf{A}(\vec{\theta}, \vec{\phi})$ and $\mathbf{C}:=\mathbf{C}(\vec{\theta}, \vec{\phi})$ depend on the parameters in (3.1), (3.2) and (3.3), $\vec{\theta}:=\left(\bar{\beta}, \gamma, \lambda, \kappa_{1}, \kappa_{2}, \omega, \mu, \chi\right)$; and also the policy parameters $\vec{\phi}:=\left(\phi_{\pi}, \phi_{x}, \phi_{s}\right)$.

Local stability of a REE depends on the eigenvalues of matrix A. Following the terminology of Blanchard and Kahn [1980], we can see that there are three non-predetermined variables. Therefore, the equilibrium under DITR will be determinate if the three eigenvalues of $\mathbf{A}$ are outside the unit circle, whereas it will be indeterminate when at least one of the three eigenvalues of $\mathbf{A}$ is inside the unit circle. Unfortunately, we are not able to obtain analytical characterizations of the stability conditions for each class of policy rules. We numerically check for determinate REE (and similarly check for multiplicity of REE) as functions of the policy parameters. In particular, we consider $\phi_{\pi} \in[0,4]$ and $\phi_{x} \in[0,4]$, as in Llosa and Tuesta [2008], and vary $\phi_{s}$ where relevant.

What we have shown previously, is that the inability of a small open economy to completely insure its country-specific technology risk results in an endogenous trade-off for monetary policy. This outcome does not exist in the canonical NK closed economy nor the complete-markets small open economy models (recall the discussion in section 4). This feature poses additional restrictions on the admissibility of the classes of policy rules in terms of inducing a determinate REE.

We will illustrate the following conclusions. First, market incompleteness results in an opposite conclusion to the finding in Llosa and Tuesta [2008]. Llosa and Tuesta [2008] showed that the set of admissible DITR (that respond to contemporaneous variables) inducing unique REE, in a small open economy with complete markets, is larger than that in its closed-economy limit. In general, we find that market incompleteness makes the admissible policy sets smaller than when we have the limit of the complete-markets small open economy. In the specific case of the DITR, international asset market incompleteness also reduces the admissible policy space relative to when we have the closed-economy limit. Second, if the policy rules are of the forecast-based families (FB-DITR, FB-CPITR and FB-MERTR), then market incompleteness in our model also shrinks the sets of these policies that can induce unique REE, relative to their counterparts in the special case of the complete-markets small open economy model. Third, if monetary policy can be described by simple policy rules, then a contemporaneous rule (MERTR) that not only responds to domestic inflation and output gap, but also to the real exchange rate growth, can greatly expand the feasible set of such policies in inducing determinate rational expectations equilibrium. This result is also well-known in the context of small open economies with complete markets [see e.g. Llosa and Tuesta, 2008].

\section{D.4 Additional policy rules and numerical results}

FB-DITR. Figure 4 shows the sets of FB-DITR policies (D.8) that induce unique REE for our IM economy, the limit economy CM and also the limit of the CD economy. Again, we see that the set of FB-DITR 
inducing indeterminate REE is larger than that of DITR, and the set of rules inducing indeterminate REE is larger in the IM economy than in the $\mathbf{C M}$ economy. This set is larger in the $\mathbf{C M}$ economy than in the CD economy.

\section{[ Figure 4 about here. ]}

This example policy illustrates that responding to expectations of future domestic inflation and output may be counterproductive in achieving determinate REE. We can glean some intuition again from the observations in Section 4.2. In particular, in the closed- and complete-market-open-economy limits, the contemporaneous trade-off between domestic inflation and output gap is not conditioned at all on expectational variables. Hence, a policy rule that responds to expectational variables will turn out to fuel more instability or at least self-fulfilment in expectations. In a weaker sense, in the incomplete-markets case, although the trade-off now depends on expectational variables, what is crucial is the indirect management of expectations of exchange rates in the policy response that would matter.

CPITR. Next we also consider a variation on the DITR, the CPI Inflation Targeting Rule (CPITR), as in equation (D.9). However, the authority and agents in the economy know that in equilibrium, there is a relationship between CPI, domestic inflation, and the real exchange rate, given by $\pi_{t}=\pi_{H, t}+\frac{\gamma}{1-\gamma}\left(\widetilde{q}_{t}-\right.$ $\left.\widetilde{q}_{t-1}\right)$. Then the CPITR can be equivalently written as

$$
r_{t}=\phi_{\pi} \pi_{H, t}+\phi_{x} \widetilde{x}_{t}+\frac{\gamma \phi_{\pi}}{1-\gamma}\left(\widetilde{q}_{t}-\widetilde{q}_{t-1}\right)
$$

Note that for the CM economy, we can use the complete cross-country risk sharing condition in (4.1), so that CPITR in this limit economy becomes,

$$
r_{t}=\phi_{\pi} \pi_{H, t}+\left(\phi_{x}+\frac{\tau \gamma \phi_{\pi}}{1-\gamma}\right) \widetilde{x}_{t}-\frac{\tau \gamma \phi_{\pi}}{1-\gamma} \widetilde{x}_{t-1}, \quad \tau:=\frac{\sigma(1-\gamma)}{(1-\gamma)^{2}+\sigma \eta \gamma(2-\gamma)}
$$

In the CD economy case, CPITR is identical to its DITR. As before, by combining (D.14), or (D.15), or the DITR with the equilibrium characterizations in each of the respective three economies, we can then numerically characterize the stability conditions for a REE under CPITR.

Figure 5 depicts our findings for these rules. Openness to trade under complete markets (CM) reduces the set of CPITR policy that induces REE indeterminacy, compared to the CD economy. However, incomplete asset markets (IM) expands the set of CPITR policy that induces indeterminate REE from that of the CM economy. Observe that qualitatively, the order of the indeterminacy sets under CPITR are identical to DITR. Numerically there is a small gain in the stable REE regions for CM and IM.

[ Figure 5 about here. ]

The general intuition is consistent with our reasoning previously for DITR. However, the CPITR rules also respond to real exchange rate growth in the IM economy. Such stabilizing rules help to regulate or act as a speed check on expectations of the exchange rate and output gap; and these prevent even more unstable expectational spiral in inflation, amplified through the endogenous cost-push term $\omega_{t}$ in (4.9). 
Hence there is some additional stability gain in using CPITR over the DITR rules. In the CM economy, the class of CPITR rules is equivalently a speed check rule on output gap, as shown in (D.15).

FB-CPITR. Consider next, a forecast-based version of the CPITR or FB-CPITR in equation (D.10). Again, using the CPI inflation relation with domestic inflation and real exchange rate gap, this rule can be written as

$$
r_{t}=\phi_{\pi} \mathbb{E}_{t}\left\{\pi_{H, t+1}\right\}+\phi_{x} \mathbb{E}_{t}\left\{\widetilde{x}_{t+1}\right\}+\frac{\gamma \phi_{\pi}}{1-\gamma}\left(\mathbb{E}_{t} \widetilde{q}_{t+1}-\widetilde{q}_{t}\right)
$$

for the baseline IM economy, and,

$$
r_{t}=\phi_{\pi} \mathbb{E}_{t}\left\{\pi_{H, t+1}\right\}+\left(\phi_{x}+\frac{\tau \gamma \phi_{\pi}}{1-\gamma}\right) \mathbb{E}_{t}\left\{\widetilde{x}_{t+1}\right\}-\left(\frac{\tau \gamma \phi_{\pi}}{1-\gamma}\right) \widetilde{q}_{t}
$$

in the case of the CM economy.

Compared to the CD economy, the set of FB-CPITR inducing determinate REE is smaller. However, this set (CM) is larger than in the (IM) economy with FB-CPITR.

\section{[ Figure 6 about here. ]}

Again, this example policy illustrates that responding to expectations of future CPI inflation and output may be counterproductive in achieving determinate REE. The intuition is as before. In the closed- and complete-market-open-economy limits, the contemporaneous trade-off between domestic inflation and output gap is not conditioned at all on expectational variables. Hence, a policy rule that responds to some of these variable may turn out to deliver less cases of stabilizing policies. In a weaker sense, in the incomplete-markets case, although the trade-off now depends on expectational variables, what is crucial is the indirect management of exchange-rate expectations in the policy response, through managing current growth, that would matter. 
Table 5: General IM model's REE characterization

\begin{tabular}{lc}
\hline \hline Composite Parameter & Value \\
$\lambda$ & 0.0719 \\
$\kappa_{1}$ & 8.8033 \\
$\kappa_{2}$ & -12.3424 \\
$\omega$ & 1.0000 \\
$\mu$ & 1.0320 \\
$\chi$ & $3.2 \times 10^{-7}$ \\
\hline
\end{tabular}

Table 6: Comparing REE characterizations-general model

\begin{tabular}{lccccc}
\hline \hline & \multicolumn{2}{c}{ IM } & \multicolumn{2}{c}{ CM } & CD \\
& $\delta=0.114$ & $\delta=0$ & $\delta=0.114$ & $\delta=0$ & $\delta=\gamma=0$ \\
\hline$\lambda \kappa_{1}$ & 0.6325 & 0.7556 & 0.1169 & 0.1235 & 0.4695 \\
$\lambda \kappa_{2}$ & -0.8868 & -1.0872 & 0 & 0 & 0 \\
$\mu$ & 1.0320 & 1.0320 & 1.0320 & 1.0320 & 0.2 \\
\hline \hline
\end{tabular}


Figure 4: Forecast-based domestic inflation targeting rule (FB-DITR) and indeterminacy for three economies. Non-shaded region refers to stable REE cases.

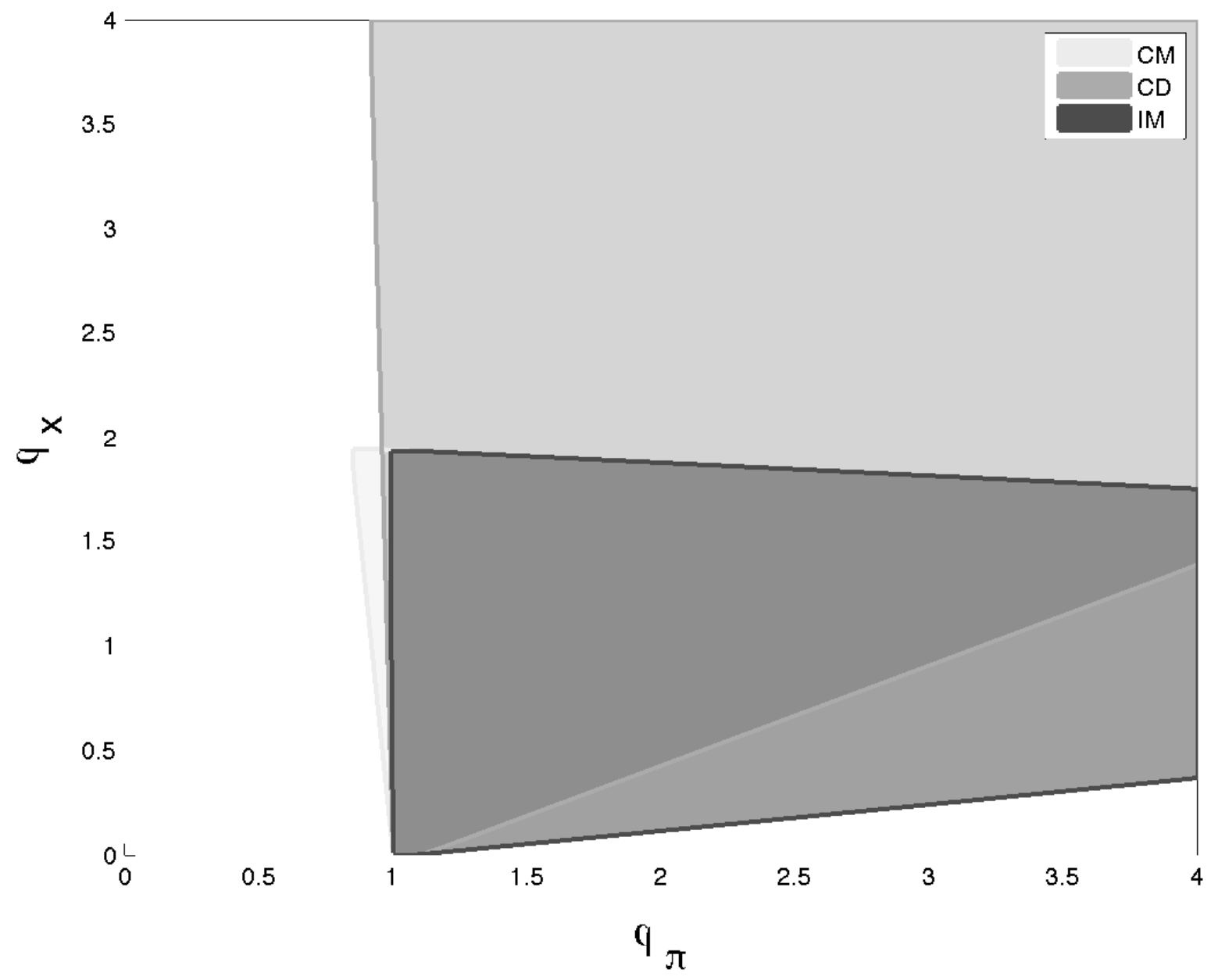


Figure 5: CPI inflation targeting rule (CPITR) and indeterminacy for three economies. Nonshaded region refers to stable REE cases.

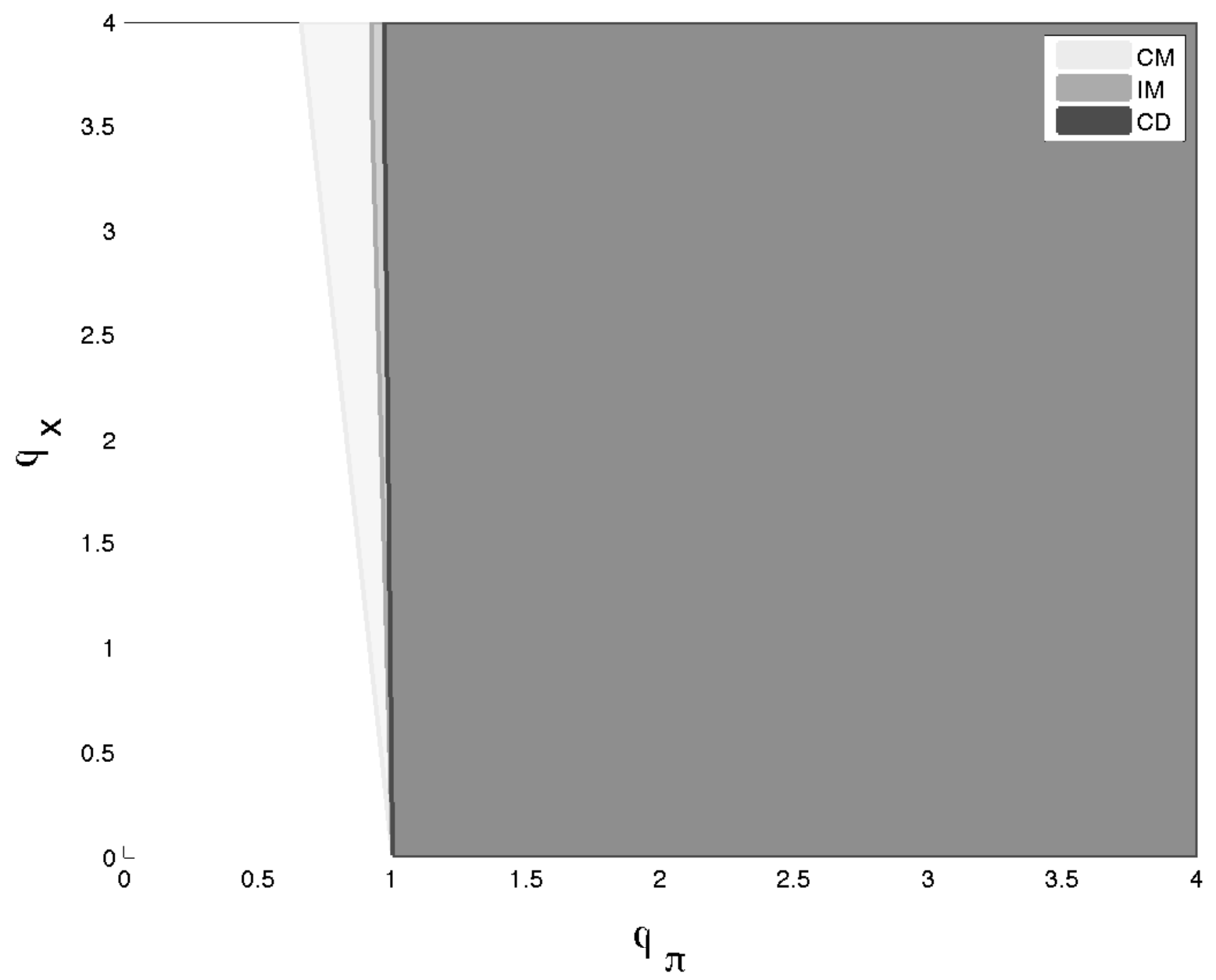


Figure 6: Forecast-based CPI inflation targeting rule (FB-CPITR) and indeterminacy for three economies. Non-shaded region refers to stable REE cases.

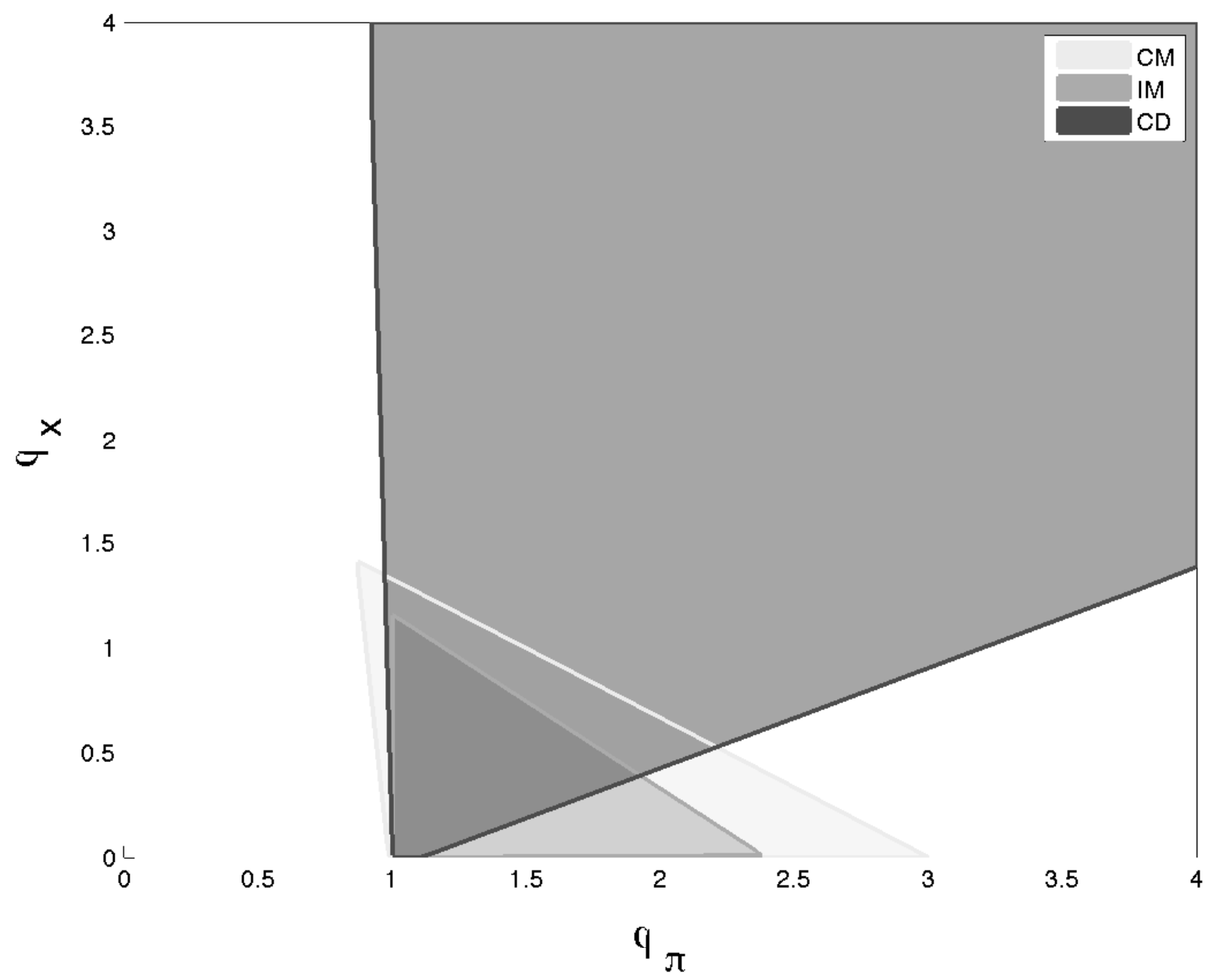

